\title{
Valence Creation and the German Applicative: The Inherent Semantics of Linking Patterns
}

\author{
Laura A. Michaelis \\ University of California at Boulder
}

\author{
Josef Ruppenhofer \\ University of California, Berkeley
}

\begin{abstract}
We provide a unified account of semantic effects observable in attested examples of the German applicative ('be-') construction, e.g., Rollstuhlfahrer Poul Schacksen aus Kopenhagen will den 1997 erschienenen Wegweiser Handiguide Europa fortführen und zusammen mit Movado Berlin berollen ('Wheelchair user Poul Schacksen from Copenhagen wants to continue the guide 'Handiguide Europe', which came out in 1997, and be-roll Berlin together with Movado.'). We argue that these effects do not come from lexico-semantic operations on 'input' verbs, but are instead the products of a reconciliation procedure in which the meaning of the verb is integrated into the event-structure schema denoted by the applicative construction. The applicative pattern is an ARGUMENT-STRUCTURE CONSTRUCTION, in terms of Goldberg (1995). We contrast this account with that of Brinkmann (1997), in which properties associated with the applicative pattern (e.g., omissibility of the theme argument, holistic interpretation of the goal argument, and planar construal of the location argument) are attributed to general semantico-pragmatic principles. We undermine the generality of the principles as stated, and assert that these properties are instead construction-particular. We further argue that the constructional account provides an elegant model of the valence-creation and valence-augmentation functions of the prefix. We describe the constructional semantics as prototype-based: diverse implications of bepredications, including iteration, transfer, affectedness, intensity and saturation, derive via regular patterns of semantic extension from the topological concept of COVERAGE.
\end{abstract}

\section{Introduction ${ }^{1}$}

Compositional theories of sentence semantics have been centrally concerned with the relationship between the meanings of lexical items and the meanings of sentences which contain those lexical items. Verbal argument structure has been of great interest in recent theory building because of the transparent nature of the relationship between the verb's semantic requirements and the number and kind of thematic roles in the sentence. The majority of theories of verbal argument structure accord a central place to the concept of ALTERNATION, exploring the nature of the relationship between argument frames licensed by a given verb. The recognition that argumentstructure alternations are licensed by narrow semantic classes of verbs (Levin 1993, Gropen et al. 1989) has led to lexically based accounts of alternations, most of which posit minimally specified verbal valence structures along with general principles ('linking rules') governing the interface between verbal thematic structure and surface syntax.

While the general principles are typically based upon some version of Fillmore's (1968) semantic-role hierarchy, the greatest attention has been paid to those cases in which linkings to 
the core grammatical functions do not follow the predictions of the hierarchy. Mappings of this type are described by two general approaches. In the first approach, semantic (e.g., Aktionsart) representation is held constant, and the marked patterns are viewed as violations of mapping constraints (Foley \& Van Valin 1984). The existence of the marked patterns may be attributed to optimization elsewhere in the system, including the achievement of a match between a given thematic role and a given functional role (e.g., location and topic in Bresnan's 1994 analysis of locative inversion). In the second approach, the mapping constraints are assumed to be inviolable, while the lexico-semantic representations which provide inputs to those rules are manipulated through semantic operations on decomposed lexical structure (Gropen et al. 1989, Wunderlich 1997, Rappaport Hovav \& Levin 1998).

Each model has been applied to the problem of the locative alternation. In the marked member of this alternation, a goal or location argument, which would otherwise receive oblique coding, receives the coding prototypically associated with the thematic role of patient (Foley \& Van Valin 1984, Dowty 1991, Van Valin \& La Polla 1997). This pattern, exemplified by the English sentence She smeared the canvas with paint, has been viewed as theoretically important because its interpretation, involving an attribution of 'affectedness' to the goal argument, suggests something noncompositional about the operation of the lexical rule. The lexical rule appears to be adding meaning. The facts of German, while superficially similar to those of English, force us to address an additional, more fundamental question: Is there a lexical rule at all?

At first glance, the locative alternation identified in English finds a straightforward parallel in German, with two obvious differences. First, the oblique-promoting device in German, like the applicative pattern in Bantu languages (Alsina \& Mchombo 1990, Wunderlich 1991), involves morphological marking on the verb-in the case of German, the inseparable prefix be. Thus, for example, the applicative counterpart of the German verb schmieren ('smear') is beschmieren, as in Sie beschmierte die Leinwand mit Farbe ('She smeared the canvas with paint'). Second, the German applicative linking pattern combines with both intransitive and transitive verbs. That is, it accepts not only trivalent transitive verbs denoting transfer, e.g., schmieren, but also bivalent intransitives denoting location or locomotion, e.g., wandern ('wander'). Accordingly, the verb wandern has the bivalent transitive counterpart bewandern, as in Sie bewanderte den Schwarzwald ('She wandered the Black Forest'). In both the trivalent and bivalent conditions, the location argument, which would otherwise receive oblique (preposition phrase) coding, is expressed by a direct grammatical function (a direct object when the voice is active). In the latter case, the applicative has a TRANSITIVIZING function. As a number of theorists, including Marcus et al. 1995 and Brinkmann 1997, have observed, the German applicative pattern is both productive and constrained: a great many verbs have applicative alternates and yet these verbs appear to cluster into relatively narrow semantic classes. In this regard, of course, the German 
applicative behaves much like its English analog, as described by Pinker 1989 and Levin 1993, inter alia. For example, causative verbs of position like English lean (or German lehnen) do not generally form acceptable applicative sentences, as in, e.g., *She leaned the field with ladders.

All of the foregoing observations are consistent with a model of the German applicative pattern in which a lexical rule mediates between two entries for a given verb. This general type of model works whether the alternating verbs are bivalent or trivalent and whether or not the two verb entries related by the rule are assumed to contain identical sets of semantic entailments. However, a more comprehensive look at the inventory of verbs which license the applicative pattern in German suggests that we need a different conception of the function of this pattern than that suggested by lexical-rule based approaches. This broader picture includes examples which cast doubt upon the general claim that the German applicative is a device for 'promoting' location arguments that would otherwise receive oblique coding. In certain of these examples, illustrated in 1, the 'input' lexical entry is (arguably) trivalent but does not license a goal argument:

<61XJdRgaxSB@p-klink.link-dd.CL.sub.de>

Aber wenn ich es mir recht überlege habe ich mich von meinen Kollegen [...] auch mal eifrig mit Kaffee bekochen lassen und bin lange nicht darauf gekommen, daß das auch was mit dem Autoritätsnymbus des Vorgesetzten zu tun haben könnte und nicht nur mit Sympathie.

'But, if I remember correctly, I also often got myself be-cooked with coffee by my colleagues, and I didn't realize for a long time that this [service] might have to do with the authority vested in a superior and not just with being liked.'

In 1, be-prefixation has an effect similar to that of the English ditransitive pattern in allowing the linking of a BENEFICIARY argument to a core grammatical function (cf. He made them coffee). The base verb in 1, kochen ('cook'), does not license an oblique expression denoting a goal, as illustrated by the ill-formed permutation *Ich habe meine Kollegen Kaffee zu mir kochen lassen, whose English translation is the equally ill formed *I had my colleagues make coffee to me. In certain bivalent applicative examples, exemplified in 2 , the base verb could conceivably be said to subcategorize for a location argument, but assigns this argument direct rather than oblique coding:

Message-ID: <37ba6d95@news.dvs.org>

Es reicht Selzer, hier andere aufrichtige Leute als Neonazis zu beschimpfen und anderweitig zu verleumden geht zu weit. 
'That's enough, Selzer! Verbally abusing (lit. be-scolding) other decent people by calling them Neo-Nazis and slandering them in other ways goes too far.'

In 2, the bivalent base verb schimpfen ('scold') is transitive rather than intransitive; the 'location' argument (the recipient) receives direct-object coding in both applicative and nonapplicative alternates. The relationship between schimpfen and beschimpfen is therefore not analogous to that which holds between other bivalent verbs like wandern ('wander') and bewandern: be-prefixation in 2 does not transitivize. Another problematic class of bivalent applicative verbs are those whose base verb is monovalent. This class is exemplified in 3 for the verb lügen ('lie'):

<37CCFA53.12B18AA2@t-online.de>

Die Teilnehmer an dieser Studie haben 36 Fragen beantwortet, z. B. wieviel Zeit sie im Internet verbringen, zu welcher Uhrzeit, welche Teile des Internets benutzt werden, ob es Probleme mit Partnern oder Freunden wegen der langen Sessions gibt, ob sie schon versucht haben, die Sitzungen zu kürzen und wie es ihnen damit gegangen ist und ob sie schon andere in bezug auf die Zeit, die im Internet verbracht wurde, belogen haben.

'The participants in this study answered 36 questions, for instance: how much time do they spend on line, at what time (of day), which parts of the Internet are being used, whether there are problems with friends and partners/spouses because of the long [browsing] sessions, whether they have tried to shorten the sessions and how that worked out, and whether they have deceived (lit. be-lied) others concerning time spent on-line.'

Unlike its ostensible English counterpart lie, lügen does not accept an oblique argument expressing the party deceived. The sentence *Er log mir über den Unfall ('He lied me [dative] about the accident') is ill formed, as are the variants illustrated by *Er log auf/zu/gegen mich über den Unfall ('He lied on/to/against me about the accident'). Therefore, the applicative verb in 3 could not be said to code as a direct argument what would otherwise be coded as an oblique (preposition phrase or dative). Instead, the applicative pattern itself appears to license the 'malefactee' argument. This licensing effect is not limited to that of merely augmenting verbal valency. In our final class of cases, exemplified by 4 , the input form lacks valency entirely; it is a noun rather than a verb:

Message ID<1998090913374500.JAA19465@ladder01.news.aol.com>. 
Es mag ja lustig sein, zwei hartgekochte Eier wie Clownsköpfe mit angekeimten Sojabohnen zu behaaren und sie auf Gurkenscheiben zu stellen, ihnen mit zwei Tomatenstreifen Münder zu verpassen und Auglein aus Sojasprossen einzudrücken.

'OK, it might be funny to be-hair two hard-boiled eggs like clown's heads with germinating soy beans, to stand them up on cucumber slices, to give them mouths from tomato strips, and to impress soy shoots on them as little eyes.'

In 4, a trivalent applicative predication, the base form is the noun Haar ('hair'). There is no transfer verb *haaren ('hair'). The applicative predication in 4 denotes a transfer event of the type denoted by trivalent applicative verbs like laden ('load'), and yet the transfer implication cannot be attributed to the semantics of the base form, which in this case is not a verb, let alone a transfer verb. In all of the examples 1-4, the appropriate inputs are simply lacking. These examples therefore suggest that the lexical-rule based model of the applicative pattern is inadequate.

These examples also disturb the neat picture of constrained productivity presented above. They suggest that the applicative pattern is not as selective about its inputs as previous analyses have implied; the pattern combines with verbs which do not denote either transfer or location. This fact makes it more difficult to describe the use conditions upon the applicative. One could claim that the tokens in 1-4 are idiomatic or marginal uses which do not bear upon the function of the applicative. However, 1-4 illustrate productive uses. Applicative predications like the denominal in 4 are novel, and in fact many of the novel tokens used to illustrate the productivity of the German applicative involve verbs which do not have base forms denoting transfer, locomotion or location. Brinkmann (1997:11), for example, cites as evidence of the productivity of be-prefixation relatively unconventional attested tokens, including bestreifen (a denominal verb meaning 'patrol an area' for which a verbal base form *streifen is lacking) and bedudeln (roughly, 'drone someone'), whose base form is the intransitive verb dudeln ('play tunelessly'). These novel examples of be-prefixation have little relevance for the productivity of the locative alternation, since they do not illustrate it. If we assume that the productivity of a form is evidence of a specific function, and that the function of the applicative pattern cannot be 'locative promotion', then we face the challenge of discovering what function of be-prefixation accounts for both novel denominals like 4 and the examples typically used to illustrate the locative alternation.

Even were we to broaden the function of the applicative to that of promoting any argument otherwise expressible as a preposition phrase (and not merely a locative argument), we would encounter difficulty. This more general version of the oblique-promotion analysis appears at first 
to be valid: certain bivalent $b e$-verbs which do not qualify as verbs of location nevertheless have bivalent intransitive counterparts which license a prepositional phrase. Brinkmann (1997: 84-85) points to several verb classes in which such alternations can be found, including verbs of active perception, verbs of speech, and verbs of emotional expression. Pairs exemplifying alternations in each class are, respectively, riechen an/beriechen 'sniff [e.g., a flower]/sniff thoroughly'; sprachen über/besprachen 'talk about/discuss'; and weinen um/beweinen 'cry about/mourn [e.g., a death]'. However, the broader alternation-based model would not extend to bivalent applicative verbs with transitive base forms (e.g., beschimpfen in 2) or to bivalent applicative verbs with monovalent base forms (e.g., bedudeln). The latter class of verbs includes not only belïgen in 3 but also applicatives formed from other verbs of deception, including schummeln and mogeln ('cheat') and schwindeln ('fib'). Moreover, the more general model of the applicative alternation does not encompass applicative verbs which lack verbal base forms entirely, e.g., bestreifen ('bepatrol') and the denominal applicative behaaren in 4. Thus, even a very broad conception of the 'promotion' function of the applicative is too narrow.

If we abandon the idea that the applicative pattern is an argument-promotion device, we must then ask whether it is used to achieve semantico-pragmatic effects that are not derivative of the promotion function. It would be a challenge to isolate and describe such effects, if they exist. The examples in 1-4 demonstrate that the range of meanings associated with be-prefixed verbs is large, and includes an 'affectedness' implication (1,3), an intensive-action implication (2), and a transfer implication (4). Do these meanings have anything in common? Ironically, the very characteristic of be-prefixation which makes it worthy of an in-depth synchronic study-its high type frequency_also appears to point toward a bleached rather than rich semantics (Eroms 1980). The number of be-prefixed verbs is considerable: more than 500 such forms appear in dictionaries. When a common semantic denominator is recognized, it is generally highly schematic, and not obviously attributable to the presence of the prefix. Wunderlich (1987), for example, proposes that be-predications express 'topological local proximity'. Others have proposed a general implication of 'affectedness' of the object-denotatum (Filip 1994). Both of these analyses seem plausible, and yet the implications in question can also be analyzed simply as properties of the semantic prototype associated with transitive predications (Hopper \& Thompson 1980, Hopper 1985).

Accordingly, we reject the idea that there is a single abstract meaning associated with the applicative pattern. Instead, we propose to capture the commonalities among usages of the bepattern through an associative network based on a single SEMANTIC SCHEMA (Goldberg 1995, Lakoff 1987). This schema is one in which a THEME physically covers a LOCATION (either over the course of time or at a given point in time). We will propose that this schema is the basis for certain metaphorical extensions. The relationship between the schema and these metaphorical 
extensions will be represented by links denoting metaphorical mappings (Goldberg 1995, Lakoff 1987). These links include the following independently motivated metaphorical mappings (Reddy 1979, Lakoff \& Johnson 1980, Sweetser 1990, Goldberg 1995): DISCOURSE IS TRAVEL OVER AN AREA, PERCEIVING IS COVERING OBJECTS WITH ONE'S GAZE, THE CONDUIT METAPHOR, EFFECTS ARE TRANSFERRED OBJECTS. We further propose that, through a mode of grammaticalization called PRAGMATIC STRENGTHENING (Hopper \& Traugott 1993, König \& Traugott 1988), the applicative pattern has also come to express TRANSFER, ITERATED ACTION, INTENSIFICATION of the action or state denoted by the verb, and EFFECTS achieved by means of an action. These inference-based extensions conventionalize prototypical components of applicative semantics, while canceling entailments related to coverage. An analysis of this type will allow us to capture the notion that be-predications form a coherent semantic group, although a given pair of be-predications may have few semantic commonalities.

In our proposal, the semantic features shared by applicative verbs are contributed by the argument-structure pattern with which those verbs combine. This proposal counters an analytic trend. While proponents of lexical-rule based approaches appear to agree that semantic constraints determine whether a linking rule can APPLY, most appear highly uncomfortable with the idea that a linking rule can CONTRIBUTE conceptual content not found in the input verb. Thus, Gropen et al. 1991 and Pinker 1989, argue that the 'affectedness' implication associated with oblique-promoting patterns is a general implication of direct-object coding rather than a meaning component contributed by the linking rule (see also Lebeaux 1988, Rappaport \& Levin 1988, Tenny 1987). This position makes sense against the backdrop of an alternation-based model, in which linking rules neither create nor destroy any aspect of thematic structure. The effect of a linking rule is thereby limited to that of altering the expression of participant roles. Since the examples in 1-4 call into question the principle of conservation of thematic structure, they also call into question its corollary-the proposition that linking rules do not contribute meaning to sentences.

We will argue that the meanings of examples like 1-4 are products of a reconciliation procedure in which the meaning of the verb is brought into conformity with the meaning of the applicative pattern. On this model, the be-prefix is a morphological feature of the applicative pattern, rather than a device for deriving new verbs or verb entries. The applicative pattern is an ARGUMENT-STRUCTURE CONSTRUCTION, in the sense of Goldberg (1995). Such constructions are linking templates which denote basic-level event types (like transfer and caused motion). As Saussurean signs, these pairings are highly similar to verbs. Both verbs and argument-structure constructions have (a) thematic and Aktionsart structure, (b) meanings which are subject to systematic extension, and (c) idiosyncratic usage constraints. The conception of grammar as a hierarchically organized inventory of form-meaning pairs (with greater and lesser degrees of 
internal complexity) is central to CONSTRUCTION GRAMMAR (CG) (Zwicky 1994, Kay \& Fillmore 1999, Goldberg 1995, Michaelis \& Lambrecht 1996, Jackendoff 1997b). We will argue that widely identified interpretive properties of the German applicative pattern are idiomatic properties of the applicative construction, and that attempts to attribute these properties to general semantico-pragmatic principles have failed.

In the CG model of argument structure as proposed by Goldberg, the semantic effects observable in 1-4 do not result from 'derivations' in which a restricted set of 'input verbs' undergoes modification of semantics and syntax, whether in the lexicon or elsewhere. In the CG model, verbs do not have alternate semantic representations. Instead, verb meaning is constant across syntactic contexts. No additional lexical entry is created to represent the meaning and valency of verbs found in specialized patterns like the ditransitive. Verbs unify with verb-level linking constructions which denote event types. These linking constructions assign grammatical functions to participant roles contributed by the verb. In addition, since these constructions denote event types, each licenses the theta frame entailed by its particular event type. This set of thematic roles may PROPERLY INCLUDE the set of roles licensed by the verb. In such cases, verbs which combine with the construction undergo modulation of their theta frames. In the case of the applicative pattern in particular, as we will show, the construction not only AUGMENTS verbal valency but CREATES valence patterns for open-class items which are not inherently relational. We will argue that the function of valence building cannot be revealingly modeled by lexical-rule accounts, while this function is predicted by the constructional model.

This paper will be structured in the following way. In section 2, we will discuss a recent account of the function of be-prefixation, presented by Brinkmann (1997) as part of an acquisition study of the locative alternation in German. Although the locative alternation has been widely described, we chose to react to Brinkmann's account because it is comprehensive in its attention to previous literature, provides a clear and well articulated example of the derivational approach to argument structure, and represents a strong challenge to the view advanced here-that the semantic effects observable in 1-4 are attributable to a specific formal pattern rather than to more general principles of interpretation. In section 3 , we will more fully motivate the construction-based approach to argument structure and discuss the advantages that this approach offers to the analysis of the applicative pattern. In section 4, we will discuss the semantic schema associated with the applicative pattern, and its metaphorical and pragmatic extensions. Section 5 contains concluding remarks. 


\section{An Alternation-Based Account of the Applicative Pattern}

2.1. Overview of Brinkmann (1997). Alternation-based accounts of the meaning of the applicative pattern tend to have the following two characteristics. First, they presume that applicative verb entries are derived from corresponding nonapplicative entries by means of an abstract operation. Second, they evoke general interpretive principles in the semantic analysis of applicative sentences. Accounts of this type include Pinker (1989) for the English locative alternation and Wunderlich (1987) for German be-verbs. Brinkmann's (1997) account, which is based on Wunderlich's $(1987,1991,1997)$ accounts of German prefix verbs, also exhibits the two foregoing characteristics. First, within LEXICAL DECOMPOSITION GRAMMAR inseparable-prefix verbs that take locations as direct objects are lexically derived from their unprefixed base verbs through FUNCTIONAL COMPOSITION of a verbal predicate and a prepositional predicate. Second, all semantic effects associated with the applicative pattern are accounted for either by constraints on the verb classes that can participate in the alternation or by general interpretive principles, rather than via semantic constraints originating in the rule itself.

We will argue that these two major features of the Brinkmann account are significant weaknesses. In the following section (2.2), we will argue that the preposition-incorporation model does not provide a principled account of the valence-building function of the applicative pattern, and thereby fails to capture a major source of its productivity. In section 2.3 , we will question Brinkmann's claim that all specific semantic effects can be accounted for straightforwardly by reference to general interpretive principles and etymology. In that section, we will focus on three interpretive features of be-predications: the holistic interpretation of the goal argument, the omissibility of the theme argument, and the interpretation of the goal argument as a two-dimensional region. For each of these three features, we will show that Brinkmann's putatively general account cannot in fact be interpreted coherently without reference to semantic properties associated directly with the applicative linking pattern.

2.2. Representing valence augmentation and creation. It stands to reason that a derivational account of argument structure, in which a lexical process changes the position in decompositional structure of argument roles, should require that the relevant argument roles be present in the input representation. However, as mentioned in section 1, there are applicative verbs which manifestly violate this requirement. These verbs fall into two broad classes: denominal, deadjectival and nonce $b e$-verbs, on the one hand, and adjunct-promoting and valenceaugmenting deverbal be-verbs on the other. We will discuss each of these two classes in turn,

pointing to the additional layers of abstract representation which the Wunderlich-Brinkmann model requires for each class. 
One may be tempted to extend the functional-composition account of deverbal be-verbs to denominal and deadjectival be-verbs by assuming that a conversion mechanism derives simple verbs from the base adjectives and nouns before the regular preposition-incorporation mechanism applies. Even if we accept the necessity of rule ordering, such an account lacks sufficient empirical support. First, there may be no simple verb that could be analyzed as the result of noun-verb or adjective-verb conversion. This point is illustrated for denominal applicatives in our corpus by an on-line classified advertisement for a 24-needle flatbed printer in which the writer states: Er kann bis etwa 1mm starkes Papier oder Pappe benadeln ('It can be-needle paper or cardboard up to $1 \mathrm{~mm}$ [thick]'). There is no conventional source denominal nadeln. Second, even when there is a homophonous candidate verb, it may not have the appropriate meaning. Consider, for example, the verb beschildern 'put up traffic signs' in 5. It can be paraphrased accurately only by the predicate aufstellen 'put up', taking the nominal argument Schilder 'traffic signs' as shown in example 5'. A simple verb schildern exists, but its meaning is 'describe', not 'put up traffic signs'.

(5) Message ID <4lq28k\$1sr@nz12.rz.uni-karlsruhe.de>

Also *m.E.* regelt 41, wie ein Radweg zu beschildern ist und wer darauf was zu suchen hat und wer nicht, und dies unabhängig davon, ob der Radweg neben einer Straße liegt oder durch die Pampa führt.

'Well, *in my opinion* [paragraph] 41 regulates how a bike path needs to be equipped with traffic signs (lit. be-traffic-signed) and who has any business on it and who doesn't, and it does so independently of whether the bike path runs next to a street or through the middle of the prairie.'

(5’) Also *m.E.* regelt 41, wie die Schilder auf einem Radweg aufgestellt werden müssen und wer darauf was $\mathrm{zu}$ suchen hat und wer nicht, und dies unabhängig davon, ob der Radweg neben einer Straße liegt oder durch die Pampa führt.

'Well, *in my opinion* [paragraph] 41 regulates how traffic signs have to be put up on a bike path and who has any business on it and who doesn't, and it does so independently of whether the bike path runs next to a street or through the middle of the prairie.'

Similarly, the verb befreien in example 6 can be paraphrased only by the resultative construction frei bekommen 'get free, released', as shown in 6'. The simple verb freien means 'to woo' rather than 'to free, liberate'. 
Deutsche Grenzschützer befreiten die Geiseln am 18. Oktober 1977 in Mogadischu; Andrawes überlebte als einziger der Terroristen.

'Members of the German border patrol freed (lit. be-freed) the hostages on October 18, 1977 in Mogadishu; Andrawes was the only one of the terrorists to survive.'

(6') Deutsche Grenzschützer bekamen die Geiseln am 18. Oktober 1977 in Mogadischu frei; Andrawes überlebte als einziger der Terroristen.

'Members of the German border patrol got the hostages free on October 18, 1977 in Mogadishu; Andrawes was the only one of the terrorists to survive.'

The lexical decomposition account seeks to deal with applicative examples like those in 5 and 6 by making two crucial assumptions. First, it allows for phonologically empty morphemes. In the case of denominals, empty verbs with appropriate meanings, such as 'put', simultaneously host preposition- and noun-incorporation processes. ${ }^{3}$ In the case of deadjectivals, a phonetically unrealized causative morpheme (CAUSE) and an unrealized inchoative morpheme (BECOME) combine with the appropriate adjectival predicates to derive the necessary input representation. Second, the input representations of deadjectival and denominal verbs are prohibited via stipulation from being lexicalized. One can take issue with this approach on two counts. First, it is ad hoc. Second, it captures the facts only by complicating the syntax-semantics interface. This strategy is undesirable if one abides by Jackendoff's (1983:14) Grammatical Constraint, according to which a model that 'preserves a simpler correspondence of syntactic and semantic structure is to be preferred' over other models. Third, it does not explain what be-prefixation contributes to the formation of deadjectival $b e$-verbs, since the semantic representations of these verbs do not contain stative locative predicates.

Problems for the incorporation account arise even when we are considering apparently straightforward cases. There are two classes of be-verbs which appear to be compositional in the sense of having semantically aligned base verbs, but which license arguments that do not belong to the subcategorization frame of the base verb. In the first class are be-verbs which license an argument that would otherwise be an adjunct. For example, the verb wachsen 'grow' does not subcategorize for a location argument. By contrast, its applicative counterpart bewachsen does require a location argument, as shown in 7 : 
Message ID <35fa4ec9.0@ netnews.web.de>

SELBSTKLIMMER = Kletterpflanzen, die mit speziellen Haftorganen Wände oder andere Flächen direkt bewachsen, Beispiele: HAFTWURZELN bei Efeu HAFTSCHEIBENRANKEN bei Wildem Wein.

'Self-climbers $=$ climbing plants that directly be-grow walls or other surfaces with the help of special adhesive/sticky extremities, for instance, sticky roots in the case of ivy, sticky tendrils in the case of wild vine.'

Wunderlich (1991:614) concedes that '[t]o describe this [phenomenon] by functional application, we have to assume that the modifier ${ }^{4}$ turns into an argument first, and then this argument is incorporated.' In other words, it is necessary to stipulate an additional operation and to order it before the derivation of the $b e$-verb. Again, this move complicates the syntax-semantics interface. In the second class are be-verbs whose unprefixed counterparts actually disallow, whether as argument or adjunct, the expression of the 'location' role licensed by the be-verb. For example, consider the contrast between mogeln 'cheat, swindle' and bemogeln, shown in 8-9, respectively:

(8) Peter hat (*mir) beim Kartenspielen gemogelt.

'Peter cheated (*me) in cards.'

(9) Peter hat mich beim Kartenspielen bemogelt.

'Peter be-cheated me in cards.'

While it is true that at the level of conceptual structure we may assume the existence of a victim of Peter's cheating in 8, this is irrelevant to the derivation of the be-form. According to Wunderlich, argument shifting by morphological operation is only possible at the level of semantic form or at the level of thematic structure (Wunderlich 1997: 52-53). At both of these levels, the location argument of mogeln would be absent. Moreover, there are deverbal be-verbs which license arguments that do not even belong to the conceptual structure of the unprefixed base verb. Consider beregnen 'be-rain, spray with water':

(10) Message ID <6xulta5r4nB@ link-m54.link-m.de>

Damals wäre um ein Haar ein Flüssiggastank in Mitleidenschaft gezogen worden...die Petershausner Feuerwehr mußte diesen daher intensiv beregnen.

'Back then a tank full of liquid gas almost got damaged. The Petershausen fire department had to make a great effort to spray water on (lit. be-rain) it.' 
The scenario of simple regnen 'rain' does not include an agent or cause of the precipitation, as shown in 11-12:

*Peter regnete die Blumen mit der Gießkanne.

'Peter rained the flowers with the watering-can.'

*Das Gewitter regnete drei Tage lang.

The thunderstorm rained for three days.

Thus, we find a multitude of cases (including apparently straightforward cases) in which the input needed by the preposition-incorporation model is unavailable. This suggests strongly that applicative semantics does not arise from operations on verbs, but instead from the imposition of a particular argument-linking pattern on a wide range of input lexical items.

2.3. Interpretive principles. Applicative predication appears to have several idiosyncratic semantico-pragmatic properties. First, the goal or location argument is generally interpreted as being affected in a holistic manner by the action which the verb denotes (HOLISM). Second, the theme arguments in transfer predications can always be omitted (NULL COMPLEMENTATION). Third, the goal argument is always interpreted as a planar region rather than, say, a threedimensional space (EXTERIORITY). According to Brinkmann, these properties are not truly idiosyncratic. She argues that the first two are instead epiphenomena of more general syntactic and pragmatic principles and that the third follows from the meaning of the prefix be-, which she analyzes as a bound preposition meaning 'on, at'. Contra these positions, we will argue in 2.3.1 and 2.3.2 that the interpretive principles as formulated cannot derive the intended semantics. In section 2.3.3 we will provide evidence that be-cannot plausibly be analyzed as a bound preposition meaning 'on, onto'.

2.3.1. Holism. Holism refers to the fact that the goal argument of a be-verb is construed as wholly affected by the action that the be-verb denotes. For instance, the sentence Die Kinder bemalten den Tisch 'The children be-painted/be-drew the table' evokes a scene in which there are drawings all over the table. This semantic characteristic of be-verbs is well known, and it is not specific to the German locative alternation: in the English sentence John painted the table it is similarly inferred that John painted the entire table surface. In his 1989 book on children's acquisition of argument structure, Pinker (1989) speculates that cross-linguistically the locationobject members of the locative alternation always serve to encode the notion of affectedness of the location and that this common function makes the alternation learnable. However, Brinkmann 
shows convincingly that this cannot be true for German be-verbs. She points out, for instance, that it is not clear in what way the cake undergoes a change of state in example 13:

(13) Donna bestreut den Kuchen mit Zucker.

'Donna be-sprinkles the cake with sugar.' (= Brinkmann 53a: 71)

Similarly, she observes that in the case of bewerfen 'be-throw' the theme need not even make contact with the goal or leave any visible traces. On the basis of such observations, Brinkmann concludes that affectedness understood as change of state cannot be a defining characteristic of German $b e$-verbs. What is it then that gives rise to speakers' intuitions of holism concerning bepredications? Brinkmann argues that it is Löbner's (1990) PRESUPPOSITION OF INDIVISIBILITY. Löbner's definition of the presupposition runs as follows: 'Whenever a predicate is applied to one of its arguments, it is true or false of the argument as a whole' [translation ours]. Applied to example 13, the principle predicts that coverage with sugar must be true for all parts of the surface of the cake, since den Kuchen is the direct object of the verb bestreuen 'strew'. Nothing needs to be said about the final effect of the denoted event upon the cake.

While the indivisibility principle seems to work well for the above case, it cannot, as intended, be true for all predications-primarily because predicate-argument relations are frequently metonymic (Fauconnier 1985, Lakoff 1987). Cases of what Jackendoff (1997a) calls ENRICHED COMPOSITION are clear exceptions to indivisibility. Consider, for instance, uses of modifiers in which the modifiers do not apply in the expected way to their arguments. In what way does the adjective sad apply to book in The book was sad, or the verb begin to book in I began the book last night? Even if we disregard this particular challenge for the moment, the indivisibility presupposition faces problems. How would it apply, for instance, to the object of the verb paint in John painted the living room door if that door had a glass window in it? From observations like these it follows that the indivisibility presupposition needs to be supplemented by more specific interpretive criteria. In fact, Wunderlich (1997) has suggested interpretive principles for locative verbs which denote an agent-initiated transfer of a theme onto a location. Consider the suggested satisfaction criteria for events of hanging pictures of Johnny Depp onto a wall, as described by Brinkmann (1997: 100-101):

\section{(14) Wunderlich's satisfaction criteria}

(a) Base verb: For all y: $y$ is a picture of Johnny Depp $=>$ y is on the wall.

(b) $B$ e-verb: For all $\mathrm{z}: \mathrm{z}$ is a sub-region of the wall $\Rightarrow>$ there is a $\mathrm{y}: \mathrm{y}$ is a picture of Johnny Depp and y is located in $\mathrm{z}$. 
The sentence Peter hängte Bilder von Johnny Depp an die Wand complies with criterion 14a as long as there is more than one picture. In order for a sentence with the corresponding $b e$-verb to be true (i.e., Peter behängte die Wand mit Bildern von Johnny Depp) most of the wall must be covered with pictures of Johnny Depp. A large number of small pictures covering only part of the wall would not do, since Wunderlich's criterion $14 \mathrm{~b}$ calls for all sub-regions to be covered. At the same time criterion $14 \mathrm{~b}$ allows for the use of be-predications in situations where not every part of the location is covered, as in the case of 13. This is possible because speakers are free to adjust the size of the sub-regions that must contain something.

However, even after the addition of the satisfaction criteria there are two problems which plague the Presupposition of Indivisibility. The first problem arises from the specific formulation of Wunderlich's satisfaction criteria. Criterion $14 \mathrm{~b}$ does not appear to apply to be-verbs like beschiessen 'put under fire, fire at' and bewerfen 'throw at'. As Brinkmann points out herself, one cannot assume that the theme will actually arrive on and impact the goal. For example, it is perfectly reasonable to assert, Sie bewarfen uns eine Stunde lang mit Steinen, trafen aber keinen einzigen von uns 'They be-threw us with stones for an hour but didn't hit a single one of us'. Therefore, the suggested satisfaction criteria are not applicable to cases like bewerfen: their semantics is unexplained. The second problem involves the fact that be-verbs can satisfy the Presupposition of Indivisibility in only one way, whereas Löbner distinguishes two means by which predications may conform to the constraint. In order to explain the nature of this problem, we must first describe the distinction which Löbner draws.

Löbner observes that if the indivisibility presupposition is to have the status of a general constraint on predication ${ }^{6}$, it must also hold for sentences such as Harry boxte Moe 'Harry punched Moe'. However, under our current formulation of the Löbner model it is not clear what the right subregions of Moe would be. To account for these cases, Löbner suggests that we refine our understanding of possible partitionings of an argument. The refinement involves positing two groups of predicates. On the one hand, there are SUMMATIVE predicates. A summative predicate applies to an argument if it also applies to each of the argument's parts ${ }^{7}$ To take Löbner's example, the sentence The children are playing could denote situations in which each child is playing his or her own game; situations in which groups of children play together; or situations where all children engage in a single game. On the other hand, there are INTEGRATIVE predicates. Unlike summative predicates, these do not apply to arbitrarily chosen parts of the argument; in many cases they do not apply to any parts at all. ${ }^{8}$ There is only one admissible partition of the argument, the zero-partition; the argument must always be viewed as an undivided whole. Good examples of integrative predicates are those denoting shape or weight. The sentence The pieces of the puzzle form a rectangle does not entail that each piece individually is rectangular or that arbitrary combinations of pieces form rectangles also. Another example of an integrative predicate 
is knock-kneed. If somebody is knock-kneed, it is strictly speaking only his or her legs that have this particular shape. Since one cannot pick body regions at random and predicate of them that they are knock-kneed, one must classify the predicate as integrative. Now, based on the observation that the sentence The children are playing, which has a summative reading, also has a zero-partition reading under which all children engage in a single game, it is argued that integrative predicates are really just the limiting case of summative predicates. Understood in this way, integrative predicates fall under the indivisibility presupposition.

However, once we assume that all verbs fall into one of two classes of 'indivisible' verbs, we lack an explanation for the fact that the vast majority of $b e$-verbs have summative readings with respect to their location arguments, even though they would also comply with the indivisibility presupposition if they had integrative readings. For instance, predications containing the verb beladen 'load' are summative: each part of, say, a truckbed must have a load on it. Yet there is no principled reason to presume that predications containing transfer verbs like beladen would not be integrative. Why couldn't the truckbed be viewed as the only relevant sub-region without being further divisible? In other words, why couldn't putting anything anywhere on the back of a truck be called beladen, since punching a person anywhere is punching that person? As Löbner himself points out, one cannot determine whether a predicate is summative or predicative by looking only at an argument: a person could be viewed holistically as the object of punch or as being composed of parts and regions as the object of bespritzen 'be-splash'. Given that the semantics of the goal argument does not favor one kind of reading over the other and given that both summative and integrative predicates in principle comply with the indivisibility presupposition, we conclude that the applicative pattern itself must be what gives rise to the summative readings of $b e$-verbs.

2.3.2. Theme omissibility. When a $b e$-verb denotes a transfer scenario with an agent, theme, and goal, the theme can be omitted in surface syntax, when its referent is recoverable from context, as in 15:

(15) Die Jugendlichen besprühten die Wand (mit Farbe).

'The youths sprayed the wall (with paint).'

Brinkmann argues that this fact is predicted by what she calls the NONINDIVIDUATION HYPOTHESIS. A theme is said to be nonindividuated if it is an unbounded mass or plexity, and is thereby not INCREMENTAL, in the sense of Dowty (1991). When an entity is an incremental theme, each part of that entity is mapped to a temporal subpart of an event. The theme argument in 15 , and other goal-object sentences, is nonincremental, i.e., nonindividuated. Properties of the 
theme argument do not determine the endpoint of the event described, since it is wall space and not paint whose gradual exhaustion defines the time course of the spraying event in 15 . Brinkmann provides a general motivation for the nonindividuation of the theme argument in examples like 15 by assuming that such predications denote processes. Accomplishment verbs, like sing, which otherwise select for an incremental theme, yield processual (activity) readings when their theme arguments are deindividuated, as in I sang songs. By the same token, she argues, the applicative pattern renders the theme's quantificational properties irrelevant by yielding a process reading of a verb like laden, which would not otherwise have one (p. 120). Examples of null-object complementation, e.g., I read or She smoked, are given as support for the idea that 'there is a close relationship between an incremental theme's omission from object position and its construal as nonindividuated' (p. 115).

While we concur with Brinkmann that nonspecific oblique themes of goal-object constructions are nonincremental, we will call into question two assumptions which she makes in her explanation of the nonindividuation hypothesis. The first assumption is that the omissibility of the theme is determined by semantics alone. The second assumption is that nonindividuation of the theme-and thereby its omissibility-comes about because applicative verbs are processual. Let us now look at the way in which these two assumptions are expressed. Brinkmann gives the nonindividuation hypothesis two very different formulations. In the chapter on nonindividuation (chapter 4), the notion is defined as follows:

(16) The direct object of a transitive locative verb may be omitted only when the quantificational properties of the corresponding argument are irrelevant; the argument may then be existentially bound. (Brinkmann 1997: 113)

The statement in 16 appears to express a necessary, and not sufficient, condition on omission of the theme argument: it restricts the conditions under which omission can occur ("the direct object may be omitted only when...'). However, it appears that 16 must be taken as a sufficient condition as well, since it is clearly intended as an explanation for the applicative linking. This explanation runs as follows: 'The theme does not need to be expressed syntactically, and this renders the object position available for the goal' (p. 249). In other words, 16 does not merely capture the observation that the theme arguments of trivalent applicatives are omissible; instead, it is intended as an answer to the question: 'Why do alternating transitive verbs allow the theme not to be expressed in object position?' (p. 248). That is, 16 is intended to predict the conditions under which theme arguments are omissible. 
If we in fact take 16 as a sufficient condition on omission, there is a good deal that must be read into it. By 'direct object of a transitive locative verb' we assume that Brinkmann intends that argument which would be the direct object of a transitive transfer verb if this verb were not subject to the applicative linking. That is, Brinkmann is referring to the theme argument. In requiring that the quantificational properties of this argument be 'irrelevant', Brinkmann is presumably not targeting nonincremental themes in general but only nonincremental themes which could otherwise be incremental. Without the provisos just mentioned, 16 might be taken as predicting omissibility in the case of a bivalent transitive verb like enthalten ('contain'). This verb appears to meet the conditions set out in 16: it is transitive, assigns a locative and a theme, and does not take an incremental theme. However, one could not explain one's failure to proffer a box by uttering 17 :

*Die Schachtel enthält.

'The box contains [something].'

Appropriately adjusted, 16 predicts that in a spraying scenario like 15, where we have as much paint available as needed for coverage of the surface, paint need not be the direct object of spray and, in fact, may be omitted. This is just what we find. However, examples like 18 show that 16 cannot be a sufficient condition upon omission of the theme argument. One cannot, for example, omit the theme object of a locative verb when the goal argument is linked to an oblique grammatical function.

*Peter lud auf den Wagen.

'Peter loaded [something] onto the wagon.'

Thus, the literal interpretation of the nonindividuation hypothesis generates an incorrect prediction for unprefixed transfer verbs. As we have seen, Brinkmann treats oblique status and omission as two mechanisms for nonsyntactic expression. However, it appears that oblique status and omissibility are not the same thing. Instead, omissibility of the theme appears to be dependent upon oblique status, and capturing this fact requires that one refer to a particular linking. There is nothing in lexical decompositional grammar which would obviously allow one to do so, yet Brinkmann's formulation of the hypothesis does just that by referring to direct object, a grammatical function, and quantificational properties, a semantic notion. This mixing of levels is even clearer in Brinkmann's restatement of the hypothesis in her summary chapter: 
(19) The nonindividuation hypothesis states that for a verb to take its goal as direct object, the quantificational properties of the theme must be irrelevant. The theme may then be construed as nonindividuated when it is not specified, i.e., as an unbounded amount of stuff or objects. (Brinkmann 1997: 248).

Here Brinkmann refers expressly to direct object and goal-constructs which are located at different levels of decompositional grammar. The two formulations of the nonindividuation hypothesis also reveal a theoretical inconsistency. The second formulation is stated as a condition on the use of the be-pattern, while the first is stated as condition on argument omission. The second formulation makes sense only if it is restricted to trivalent $b e$-verbs such as besprühen 'spray [a location]'. For bivalent be-verbs with theme subjects-e.g., bewandern 'hike around in', bewohnen 'inhabit', and besetzen 'occupy' as in 20-22-it is not coherent:

(20) Peter bewanderte den Schwarzwald.

'Peter be-wandered the Black Forest.'

(21) Peter bewohnt einen Apartment.

'Peter inhabits (lit. be-lives) an apartment.'

5939806:

Am Wochenende mußten 7000 Heilsuchende davon abgehalten werden, Nachbargrundstïcke zu besetzen und Straßen zu blockieren.

'On the weekend 7000 patients had to be prevented from occupying (lit. be-sitting) neighboring properties and from blocking streets.'

It is difficult to determine whether Brinkmann views 19 as a general condition on be-prefixation. She relativizes most statements of the nonindividuation hypothesis to trivalent applicatives, and throughout her analysis treats bivalent theme-subject applicatives only in passing. If 19 were to be construed as such a condition, it would not obviously extend to 20-22. These examples have a goal object, and the theme argument, the subject, is nonincremental. However, there is no sense in which this theme argument is or could be nonindividuated, since in each case the theme argument is a referentially specific entity. Clearly, 19 cannot express a general constraint on be-prefixation. The principle therefore fails to capture a crucial feature that the bivalent examples in 20-22 and trivalent examples share: the locative is the argument whose quantificational properties are relevant. A critical number of its subparts must be occupied by a theme or themes either through time (as in 20) or at a given time (as in 21-22). 
But even if we grant that the function of the applicative pattern is deindividuation of the theme argument, and limit ourselves to the trivalent cases, it seems implausible to suggest that the deindividuation (and thereby omissibility) of the theme comes from a processual reading of the verb. Omission of the theme argument of an incremental-theme verb does not entail a processual reading for that verb. For example, a predication like $I$ ate is compatible with an in-phrase of duration-a hallmark of telicity-in examples like I ate in 5 minutes so I wouldn't be late. But perhaps more importantly, sentences like 15 simply do not denote processes; they denote bounded causative events, i.e., accomplishments. Brinkmann recognizes that the processual analysis of such tokens appears at odds with the interpretive facts. However, she points out (p. 119) that the transitions denoted by trivalent applicatives, like that of a wall becoming covered with paint, do not taken place abruptly but are instead the result of a process. Therefore, she concludes, applicative predications 'denote a process that leads to a transition' (p. 119).

This claim of course is compatible with the general analysis of accomplishment predicates in decomposition-based models. The representation of accomplishment predicates contains an activity predicate (e.g., Bickel 1997, Foley \& Van Valin 1984). But if the 'output' (applicative) verb incorporates a process predicate, the 'input' verb incorporates the very same one. In what sense, then, can one say that a processual reading has been added in the case of the applicative? In addition, as Herweg (1991) demonstrates convincingly, entailing a process and being a process are two different things. If this were not so, he argues, accomplishment predications would share with activity predications the entailment pattern which he refers to as the DISTRIBUTIVITY PROPERTY (i.e., the subinterval property as per Bennett and Partee 1978). Accomplishment predicates demonstrably lack the distributivity property. Further, predications like 15 fail tests for atelicity and pass tests for telicity, particularly tests involving durational-adverb selection. It makes sense that this should be so, since the locative argument, as Brinkmann herself acknowledges (p. 121), provides the 'measuring out' function that serves to delimit the event.'

Finally, one must wonder why, in a model of the locative alternation based on lexical decomposition, there is no representation of the aspectual transformation which Brinkmann proposes. Perhaps such a representation would be incompatible with the model. An advantage claimed for the preposition-incorporation account over accounts based on affectedness is that '[it] shows how we can explain the locative alternation without positing that the verb changes its meaning' (p. 248). If no meaning change occurs, in what way can we interpret Brinkmann's claim that the applicative provides a mechanism for 'turning the verb into a predicate that specifies a process' (p. 120)? The processual reading cannot be a function of the deindividuated construal of the theme, since allowing this would create circularity: the deindividuated construal of the theme is in fact claimed to be dependent upon the processual reading of the verb. 
In sum, we have seen that the quantificational properties of the theme argument do not provide a sufficient condition for the omission of that argument and that the omission of the theme argument in trivalent applicatives cannot plausibly be attributed to a processual interpretation. Insofar as this is the case, omissibility of the theme argument appears to be a function of a particular linking (to an oblique grammatical function), and not of a general principle.

2.3.3. Exteriority. The only semantic fact about $b e$-verbs which Brinkmann attributes directly to the prefix $b e$ - is the restriction that the goal location must denote the exterior of an object (pp. 81-82). This constraint is illustrated by the ill-formedness of $23^{\prime}$ 'when intended as a paraphrase of 23. The only acceptable interpretation for example $23^{\prime}$ is that the seeds are thrown at the outside of the garbage can rather than inside it:

MessageID <667b0LdWeWB@p-ej.link-h.comlink.apc.org\#1/1>

Bin auch für Kernkraft! Überlegt einmal, wieviel Kerne wir täglich in den Mülleimer werfen, ausspucken oder verschlucken, ohne ihre Kraft zu nutzen.

'I am for nuclear power, too! Just think how many seeds (lit. nuclei) we throw into the garbage can, spit out or swallow every day without using their power.'

(23’) Bin auch für Kernkraft! Überlegt einmal, mit wievielen Kernen wir täglich den Mülleimer bewerfen, wieviele wir ausspucken oder verschlucken, ohne ihre Kraft zu nutzen.

'I am for nuclear power, too! Just think with how many seeds a day we bethrow the garbage can, how many we spit out or swallow without using their power.'

$B e-$, like other inseparable prefixes of German, lacks a corresponding free form that can be used as a preposition or particle. As Brinkmann points out, be-'s closest living relative is the preposition $b e i$, which is related to English by and has a meaning of 'by, close, near, at'. In none of its uses does bei involve contact between a theme and a landmark. Therefore, $b e$-verbs cannot be formed-synchronically at least—by incorporating bei. Brinkmann observes, however, that beverbs can be used to paraphrase unprefixed verbs with goal complements that are encoded either by auf 'on [a horizontal surface]' as shown in 24, or by an 'on [a vertical surface]', as shown in 25. Both of these prepositions have the needed meaning element 'contact with a surface'. 
(24) Ted schmierte Butter auf die Tischdecke.

'Ted smeared Butter onto the tablecloth.'

(24') Ted beschmierte die Tischdecke mit Butter.

'Ted smeared (lit. be-smeared) the tablecloth with butter.'

(25) Petra hängte Sterne an den Christbaum.

'Petra hung stars onto the Christmas tree.'

(25') Petra behängte den Christbaum mit Sternen.

'Petra hung (lit. be-hung) the Christmas tree with stars.' (= Brinkmann 5: 80)

Accordingly, Brinkmann postulates a preposition be with the same predicate-argument structure as the prepositions an and $a u f$ 'on, onto' The only difference among these prepositions is that $b e$ is a bound morpheme which occurs only as a prefix. This analysis is historically plausible, and coheres with the assumptions of the preposition-incorporation account, but its attractiveness is diminished by its idiomaticity - a particular lexical entry is created solely for the purpose of preserving a compositional account.

But even if we ignore the issue of idiomaticity and assess at face value Brinkmann's model of be- as a bound version of an or auf, we face difficulties. For if the meaning of the bound preposition $b e$-corresponds to that of the prepositions an and auf, why then are be-verbs not synonymous with an- or auf-verbs derived from the same base? Consider the following pair of sentences. While the be-sentence in 26 implies coverage of the whole tablecloth, the sentence in 27 , containing the separable prefix an-, does not.

(26) Ted beschmierte die Tischdecke mit Butter. (= 24')

(27) Ted schmierte die Tischdecke mit Butter an.

If one assumes with Brinkmann that both verbs are formed by the same process of preposition incorporation, that the prepositions involved are closely aligned semantically, and that syntactic principles such as indivisibility hold, then one would predict that 27 means the same thing as 26 , or at least that the two sentences do not differ in ways that are controlled by general grammatical principles. Yet this is exactly what we find: only the be-sentence in 26 has the expected holistic reading.

This latest finding should not come as a surprise. We have seen on several occasions that if one grants each of the premises of Brinkmann's analysis, the resulting account still does not explain all of the facts. The indivisibility principle, for instance, by its very generality fails to predict that $b e$-verbs have summative readings rather than integrative readings. Similarly, the 
preposition-incorporation model fails to extend to be-verbs like beregnen, in which the 'output' arguments are not present in the 'input' representation. These facts suggest strongly that the semantic and syntactic features of be-predications do not come from general operations and principles, but rather from a specific formal pattern to which specific semantic constraints are attached. In the next section, we will describe a syntactic theory which accords a central place to such patterns.

\section{The Constructional Approach to the German Applicative}

What would it mean to adopt a constructional rather than a lexical model of the be-pattern? We will address this question in steps. Section 3.1 will describe the nature of the challenge that Construction Grammar has offered to the principle of lexical licensing, discuss the constructional model of argument structure and set forth the constructional account of the German applicative pattern. This account rests on the assumption that the valency of verb and construction may differ. In sections 3.2-3.3.6, we will apply the constructional model to five features of the applicative pattern that proved troublesome for the Brinkmann account. In section 3.7, we will address two interrelated questions: to what extent does the constructional model adhere to Jackendoff's (1983) Grammatical Constraint and to what extent can it be described as compositional? Finally, in section 3.8, we will discuss the formal representation of applicative sentences within Construction Grammar.

3.1. Theory overview. The principle of lexical licensing holds that the basic scene denoted by a sentence (the set of participant roles expressed) derives from the argument structure of the head verb. Thus, for example, it appears clear that a sentence like We gave the account to her denotes a scene of transfer involving an agent, a theme and a goal because the semantic frame associated with the head verb give denotes a scene of transfer, and likewise requires the presence of these three participants. This principle is intrinsic to a compositional theory of semantics - a theory which has been seen as central to any account of syntax-semantics isomorphism, including that of Jackendoff, who states (1990: 9): 'It is widely assumed, and I will take for granted, that the basic units out of which a sentential concept is constructed are the concepts expressed by the words in the sentence, that is, lexical concepts'. A more recent version of this principle is stated by Jackendoff as the principle of syntactically transparent composition: 'All elements of content in the meaning of a sentence are found in the lexical conceptual structures of the lexical items composing the sentence' $(1997: 48) .^{10}$

The lexical-licensing principle has been central to the description of argument structure in most formal theories. Many such theories (e.g., Lexical Functional Grammar as described by 
Bresnan 1994 and Role and Reference Grammar as described by Van Valin \& LaPolla 1997) posit universal linking rules, which capture generalizations concerning the syntactic realization of thematic roles assigned by verbs or verb classes (e.g., the class of transfer verbs). Such theories are driven by the assumption that 'argument roles are lexically underspecified for the possible surface syntactic functions they can assume' (Bresnan 1994:91). Universal linking rules map these argument roles to grammatical and pragmatic functions, and these rules do not add to, subtract from or alter the array of thematic roles associated with the verb. For example, in Bresnan 1994, locative inversion in English and Chichewa is represented as one linking possibility for verbs of location like stand, which subcategorize for locative and theme arguments. Such verbs are subject both to the linking rule which produces the configuration in 28 and to the linking rule which produces the configuration in 29 :

Two women stood in the plaza. In the plaza stood two women.

Examples of locative inversion like 30 are, however, problematic in Bresnan's framework:

(30) Through the window on the second story was shooting a sniper.

Sentence 30 is problematic because the verb shoot assigns neither a locative role or a theme role, and yet can appear in the locative-inversion configuration. In such examples, Bresnan argues, a locative-theme argument structure imposed by the pragmatic requirement of presentational focus is superimposed on the argument structure associated with the unergative verb shoot. The agent role of shoot will consequently be identified with the 'overlay theme' (p. 91). The problem with this type of account is simply that it is not explicit. If argument structures are products of the linkings licensed by given verbs, and not independent form-meaning pairings, it is difficult to understand the source of the 'overlay theme'.

Adherence to the lexical-licensing principle results not only in ad hoc devices like an 'overlay theme' in cases like 30, but also, as Goldberg points out (1995:9ff.), appeal to implausible verb senses. Goldberg discusses examples like the following:

(31) Most likely they were fellow visitors, just panting up to the sky-high altar out of curiosity. (Lindsey Davis, Last Act in Palmyra, p. 28)

(32) As they had waved us along the raised causeway and into the rocky cleft... (op. cit., p. 31)

(33) They can't just analyze away our data. 
Goldberg points out that on the assumption that argument structure is determined exclusively by head verbs, we would need to posit a new verb sense for each of the usages exemplified in 3133. Sentence 31 would require a special sense of pant equivalent to the formulation 'move while panting'; 32 would require a special sense of the verb wave whose definition would be 'signal permission to move to a place by waving'; and, finally, sentence 33 would require one to view analyze as a verb which denotes (metaphorical) caused motion. Such word senses, as Goldberg points out are not only ad hoc and unintuitive, but also compatible only with an assumption of radical and unconstrained polysemy. Crucially, as Goldberg and Fauconnier \& Turner (1996) have demonstrated, examples like 31-33 cannot easily be viewed as marginal or special cases. Sentence 31, for example, exemplifies a lexicalization pattern-conflation of manner and motion-which Talmy (1985) and Slobin (1997) have shown to be strongly entrenched in Germanic languages. Further, the examples in 31-33 cannot be regarded merely as violations of selectional restrictions associated with the verbal heads-or even as violations which might trigger manner-based implicata. If, for example, sentence 33 merely exemplified a violation of the selectional restrictions associated with the verb analyze, we would fail to predict its wellformedness-let alone the uniformity of its interpretation across speakers; 33 is necessarily interpreted as denoting metaphorical caused motion.

Cases like 31-33 give strong evidence that the principle of lexical licensing, despite providing a parsimonious account of transparent cases like 28-29, is invalid. The alternative, constructionbased model of argument structure outlined by Goldberg is founded on a body of work, of which Talmy (1988) is representative, which focuses on universal differences in the inventory of concepts expressed by open- versus closed-class elements, and in particular on the nature of the semantic interaction between grammatical and lexical elements. Crucially, grammatical constructions are viewed as belonging to the general set of meaning-bearing grammatical elements, which includes prepositions and derivational markers. An essential tenet of these works is expressed in 34:

(34) OVERRIDE PRINCIPLE. If lexical and structural meanings conflict, the semantic constraints of the lexical element conform to those of the grammatical structure with which it is combined.

Zwicky (1989) proposes a similar universal interactional principle, which he relates to Panini's Law, since it involves the specific taking precedence over the general: 'Requirements in an evoking rule override those in an invoked rule' (p. 38). In acknowledging the applicability of 34 to cases like 31-33, we embrace the view that linking patterns are meaningful— that is, that they 
contribute schematic semantic structure distinct from that contributed by the verbs with which those patterns combine. As grammatical constructions, linking patterns are complexes of formal, semantic, and pragmatic features. On this view, we would expect linking patterns to exhibit idiosyncratic constraints. For example, we would expect that semantic constraints above and beyond those which restrict the theta frame of the input verb would be relevant for determining the applicability of a given linking pattern. These idiosyncratic constraints might include constraints on the pragmatic role or configuration of certain arguments. A prominent configuration restriction on the semantics of the be-pattern was discussed in section 2.3: bepredications, as Brinkmann observes (1997: 81) 'describe motion to the exterior of an object'.

Among the linking patterns considered by Goldberg are the ditransitive pattern (whose core semantics she captures with the formula ' $X$ CAUSES $Y$ TO RECEIVE Z'), the caused-motion pattern ('X CAUSES Y TO MOVE WITH RESPECT TO Z') and the resultative pattern ('X CAUSES Y TO BECOME Z'). Examples of each of these patterns are given in 35-37:

(35) We gave her the account.

(36) She put the checkbook on the counter.

(37) We painted the walls white.

Goldberg uses the term sentence type to refer to these linking patterns. In accordance with Fillmore \& Kay (1997: ch. 8), however, we will regard linking patterns not as sentence structures but as verb-level constructions, which unify with the lexical entries of verbs. This unification has the effect of augmenting what Fillmore \& Kay refer to as the MINIMAL VALENCE of the verb (the repertoire of semantic roles inherent to the meaning of the verb). The FULLY SPECIFIED verbal valence which results from unification of a verb's lexical entry with one or more linking constructions is one in which each semantic role is assigned a grammatical function.

A crucial assumption of Goldberg's account, which is adopted here, is the idea that the repertoire of thematic roles assigned by the linking construction may PROPERLY INCLUDE the repertoire of thematic roles in the verb's minimal valence. In 38-40 we give examples of proper inclusion for each of the linking patterns exemplified in 35-37:

(38) We painted them a landscape.

(39) She blew the dust off the picture.

(40) We cried our throats ragged.

The verb paint, a verb of creation, denotes a two-place relation, involving the creator and a created item. However, sentence 38, an instance of the ditransitive linking pattern, adds an 
additional participant to the creation scenario-a potential recipient. This recipient is not intrinsic to the creation scenario; it is instead intrinsic to the transfer scenario with which the ditransitive pattern is associated. Likewise, while the verb blow is a one-place relation, involving an agent, 39 adds two additional participants - a theme and a goal. These participants are licensed by the caused-motion construction which the sentence instantiates. Finally, in 40, the verb cry appears with two more participants than it ordinarily has-a patient and a resultant state. The additional participants are contributed by the resultant-state construction that licenses 41 .

The examples in 38-40 strongly resemble the examples in 35-37, which were used to undermine the validity of the lexical-licensing principle. Both sets of examples involve the override principle given in 34 . We can regard linking patterns like the ditransitive and causedmotion patterns as CONCORD constructions. The theta frames associated with these patterns may, and indeed typically do, match those licensed by the particular verbal head. Examples of concord, given in 35-37, are those which provide the motivation for the lexical-licensing principle. Goldberg (1997) refers to these kinds of examples as instances of INSTANTIATION, in which the verb codes a more specific instance of the scene designated by the construction. The verb may also code the MEANS by which the action designated by the construction occurs (Goldberg 1995, 1997). Examples of the means relation are given in 38-40, in which, respectively, blowing is described as the means by which the dust is moved from one location to another and crying is the means by which the hoarseness is effected. The means and instantiation relations are mutually exclusive. The means relation is operative only when the theta frame associated with the construction properly includes that of the verb.

We view the be-pattern, whose formal representation will be given in section 3.8, as a transitive linking pattern like those exemplified in 38-40. Full consideration of its semantic and linking constraints will be delayed until section 4; it is sufficient here to say, as in the introduction, that it denotes thorough coverage of a location by a theme. This general semantic scenario is compatible with two more specific scenarios, which are minimal variants of one another: a trivalent causative scenario, in which an agent is present along with locative and theme, and a bivalent scenario entailing only theme and locative. The two versions of the construction differ with regard to their valency: the trivalent licenses the theta frame <agent, theme, locative> whereas the bivalent licenses the theta frame <locative, theme>. While the bivalent version instantiates the coverage scene, the trivalent version entails that scene, in that an agent effects coverage of a location by a theme. This semantic intersection is reflected in the sharing of single linking constraint: the locative must be encoded by a direct (nonoblique) grammatical function. This situation is parallel to that described by Michaelis (1993) for Latin, in which entailment relationships between situation types, e.g., those of removal and lacking, are reflected syntactically in a shared linking constraint: the theme is ablative or genitive. 
We will use the trivalent version of the be-pattern to exemplify the semantic interaction between construction and verb. Following Goldberg (1995: 50), we will use the term FUSION to refer to the mechanism by which interpreters infer coreference relationships between arguments of the construction and participant roles assigned by the verb, where the latter are more specific instances of the former. We will assume, also in accordance with Goldberg (1995: 65), that fusion is constrained by the Shared Participant Condition: at least one argument role of the construction must be fused with a participant role assigned by the verb. The verb may bear a means relation or an instantiation relation to the constructional semantics. Sentence 41 is an example of instantiation, while sentence 42 is an example of the means relation:

(41) Sie belegte den Stuhl mit ihren Büchern.

'She be-laid the chair with her books.'

MK1/WPE.00000, PÖRTNER, DIE ERBEN ROMS, Roman

Auch die Höhen um Fulda bebauten die Mönche des frühen Klosters mit Kapellen, Kirchen und Propsteien.

'The monks of the early period of the monastery also be-built the hills around Fulda with chapels, churches, and provosts' residences.'

Example 41 exemplifies the instantiation relationship: the theta frame licensed by the trivalent verb legen is identical to the constructional theta frame. Example 42 exemplifies the means relationship between the bivalent verb bauen and the trivalent constructional theta frame. In this instance of the applicative construction, the agent role of the construction is fused with the builder role of bauen and the theme role of the construction is fused with the patient (factitive theme) role of bauen. The location role is unfused, since it is assigned by the construction alone. In the resulting predication, the verb, which denotes the creation of a structure, simultaneously denotes the means by which coverage (of the landscape surrounding Fulda) is effected. The reconciliation of verb and constructional semantics during interpretation requires the inference that multiple buildings have been built, since only on this understanding is coverage entailed.

By assuming a constructional account of argument structure, we account not only for such reconciliation effects but also for all other features of be-predications which are not proper to input verbs. These are precisely the noncompositional features of be-predications that proved troublesome for the Brinkmann account. For each of these features, we will consider the alternative account offered by a construction-based model. The phenomena to be considered are: null complementation, valence augmentation, valence creation, the exteriority constraint, and the holistic-goal constraint. 
3.2. Null complementation. As discussed in section 2.3, the pattern of nullcomplementation licensed by $b e$-verbs cannot be predicted from the constraints on the 'input' verb. The null-complementation possibilities licensed by verbs bearing the $b e$-prefix are in fact the inverse of their nonprefixed counterparts, as demonstrated by the four-way comparison in 43-44:

(43) a. Er sprühte *(Farbe) an die Wand.

'He was spraying *(paint) on the wall.'

b. Er sprühte Farbe (an die Wand).

'He was spraying paint (on the wall).'

(44) $\quad$ a. $\quad$ Er besprühte *(die Wand) mit Farbe.

'He was spraying (lit. be-spraying) *(the wall) with paint.'

b. Er besprühte die Wand (mit Farbe).

'He was spraying (lit. be-spraying) the wall (with paint).'

This comparison shows that the be-pattern in 48 licenses a null theme argument while disallowing null instantiation of the locative argument, whereas the nonprefixed pattern in 47 shows the inverse pairing of constraints. This contrast cannot be attributed to the fact that the particular thematic role is expressed as a direct object. German, like English, allows null instantiation of direct objects in cases like 45 (Fillmore 1986):

\section{Er trinkt wieder.}

'He's drinking [alcohol] again.'

Further, as discussed in 2.3, this contrast cannot, as Brinkmann proposes, be treated as purely semantico-pragmatic, since if a deindividuated construal were sufficient to permit theme omission in 43b, then theme omission should also be possible in 43a. As we see, however, theme omission appears to require certain grammatical conditions - not merely semantic ones. Under a construction-based account of argument structure, the null-complementation facts can be represented in a straightforward way. Each construction defines constraints on null complementation. In the case of the pattern exemplified in 43b, we follow Fillmore \& Kay (1997) in assuming that null complementation is licensed by a trivalent linking construction which pairs 
a locative argument with an oblique grammatical function. In the case of the be-pattern, null instantiation is licensed by a trivalent linking construction which pairs a theme argument with oblique. The constructional account of null complementation is actually implicit in Brinkmann's original statement of the Deindividuation Hypothesis, presented in section 2.3 as 16 and repeated here as 46:

(46) The direct object of a transitive locative verb may be omitted only when the quantificational properties of the corresponding argument are irrelevant; the argument may then be existentially bound. (Brinkmann 1997: 113)

Despite the fact that Brinkmann claims to have provided a general constraint governing omissibility of themes, the principle quoted above is not general but particular-it concerns a particular pairing of syntax and semantics which we will describe in section 3.8 as the OBLIQUETHEME CONSTRUCTION, a construction which unifies with the applicative construction.

3.3. Valence augmentation. As described in section 2.2, an alternation-based account cannot plausibly represent be-predications for which no 'source' or 'input' verb exists. One case of this nature is that in which the be-pattern 'adds' arguments that are not part of the theta frame of the unprefixed analog verb. One such case is that of bemogeln 'cheat', discussed in section 2.2. An attested example illustrating both prefixed and unprefixed uses of mogeln in a single passage is given as 47 :

WKD/bza.00141, Berliner Zeitung/89.12.07/s:3.

W. Schwanitz: Es ist beträchtlich. Prozentzahlen würden das verdeutlichen, die kann ich aber nicht nennen. Kein Geheimdienst dieser Erde tut das oder er mogelt. Ich will Sie nicht bemogeln.

'W. Schwanitz: It is a considerable number. Percentages would underscore this but I cannot give them. No secret service on earth does that, unless they are cheating. I don't want to be-cheat you.'

In the last sentence of 47, Ich will Sie nicht bemogeln, a malefactee argument which is not otherwise expressible appears as the direct object. An additional case of valence augmentation was discussed in section 2.3 with respect to example 7 , repeated here as 48 : 
Message ID <35fa4ec9.0@ netnews.web.de>

SELBSTKLIMMER = Kletterpflanzen, die mit speziellen Haftorganen Wände oder andere Flächen direkt bewachsen, Beispiele: HAFTWURZELN bei Efeu HAFTSCHEIBENRANKEN bei Wildem Wein.

'Self-climbers=climbing plants that directly be-grow walls or other surfaces with the help of special adhesive/sticky extremities, for instance, sticky roots in the case of ivy, sticky tendrils in the case of wild vine.'

In 48 the object function is linked to an argument whose status is that of a locative adjunct within the valence frame of the unprefixed verb (wachsen). The final case of valence augmentation discussed in 2.3 combines both aspects of valence augmentation exemplified by bemogeln and bewachsen: the direct object represents a participant role which would otherwise have adjunct status and the subject represents a participant role which is not licensed at all by the unprefixed verb. Sentences 10-12 were used to illustrate this case for the verbs regnen and beregnen in section 2.3. These examples are repeated here as 49-51:

Message ID <6xulta5r4nB@ link-m54.link-m.de>

Damals wäre um ein Haar ein Flüssiggastank in Mitleidenschaft gezogen worden [...] die Petershausner Feuerwehr mußte diesen daher intensiv beregnen.

'Back then a tank full of liquid gas almost got damaged [...] the Petershausen fire department therefore had to make a great effort to spray water on (lit. berain) it.'

(50) *Peter regnete die Blumen mit der Gießkanne.

'Peter rained the flowers with the watering can.'

(51) *Das Gewitter regnete drei Tage lang.

'The thunderstorm rained for three days.'

As we showed above, each of these classes proves problematic for an alternation-based view of argument structure, in which linking rules effect changes in the syntactic expression of some set of argument roles, but otherwise conserve thematic structure. These classes receive a straightforward and motivated account under the constructional view. On the constructional account, as described above, the valence set licensed by a linking construction may properly include that licensed by the verb with which that construction combines. Where verb and 
construction assignidentical argument roles, as in the case of the subject argument in 42, the two roles simply fuse. ${ }^{11}$ Where the theta frame of the construction contains a thematic role or roles NOT licensed by the theta frame of the verb, there is override as per the principle 34: the argument roles of the construction are 'added' as verb meaning and construction meaning are combined. What this means in the case of a sentence like 54 is that the theta frame of the verb wachsen intersects with the theta frame of the construction via the means relation. The predicateargument structure resulting from the integration of verb and construction meaning contains a participant which denotes the location covered by means of growth.

3.4. Valence creation. The limiting case of valence augmentation is that in which the head of the $b e$-predicate is not a valence-taking element in the lexicon. These are cases of valence creation, as exemplified by deadjectival and denominal be-predications. While deadjectival and denominal $b e$-verbs are highly prototypical instances of the be-pattern, the Brinkmann analysis, as we saw in 2.2 above, is forced to posit phonologically null verbs in their input semantic representations - a move which requires recourse to abstract constructs of dubious validity and the stipulation that the input semantic representation cannot be lexicalized. On the constructional account, valence creation comes about through the same highly general mechanism that underlies valence augmentation. Let us consider again the examples of valence creation 5-6 discussed in section 2.2.. These examples are repeated here as 52 and 53, respectively. For each, alternate versions 52' and 53' are given to illustrate the function of the input lexical item:

Message ID <4lq28k\$1sr@nz12.rz.uni-karlsruhe.de>

Also *m.E.* regelt 41, wie ein Radweg zu beschildern ist und wer darauf was zu suchen hat und wer nicht, und dies unabhängig davon, ob der Radweg neben einer Straße liegt oder durch die Pampa führt.

'Well, *in my opinion* [paragraph] 41 regulates how a bike path needs to be equipped with traffic signs (lit. be-traffic-signed) and who has any business on it and who doesn't, and it does so independently of whether the bike path runs next to a street or through the middle of the prairie.'

(52') Also *m.E.* regelt 41, wie die Schilder auf einem Radweg aufgestellt werden müssen und wer darauf was zu suchen hat und wer nicht, und dies unabhängig davon, ob der Radweg neben einer Straße liegt oder durch die Pampa führt.

'Well, *in my opinion* [paragraph] 41 regulates how traffic signs have to be put up on a bike path and who has any business on it and who doesn't, and it 
does so independently of whether the bike path runs next to a street or through the middle of the prairie.'

Süddeutsche Zeitung, March 4, 1996

Deutsche Grenzschützer befreiten die Geiseln am 18. Oktober 1977 in Mogadischu; Andrawes überlebte als einziger der Terroristen.

'Members of the German border patrol freed (lit. be-freed) the hostages on October 18, 1977 in Mogadishu; Andrawes was the only one of the terrorists to survive.'

(53') Deutsche Grenzschützer bekamen die Geiseln am 18. Oktober 1977 in Mogadischu frei; Andrawes überlebte als einziger der Terroristen.

'Members of the German border patrol got the hostages free on October 18, 1977 in Mogadishu; Andrawes was the only one of the terrorists to survive.'

Valence creation differs from mere valence augmentation in two respects. First, cases of valence creation involve a form-class override: the nominal or adjectival syntactic feature of the input element is overridden by the verbal syntactic feature of the construction in accordance with 34 , the override principle. Second, cases of valence creation do not involve fusion of participant roles in input and constructional theta frames, quite simply because the open-class element which combines with the be-construction in cases like 52 and 53 has no theta frame. Instead, the repertoire of roles contributed by the input item are participants in the larger semantic frame which constitutes our understanding of the socio-cultural context in which the property or entity plays a role. By semantic frames we have in mind the schemas Fillmore $(1977,1982,1985)$ uses to represent lexical semantics and which underlie his contention that all linguistic meaning is 'relativized to scenes' (1977:59). For example, in 52 the nominal Schild is meaningful only relative to a schema which includes streets and streetworkers. In 53 the adjective frei is meaningful only relative to a schema which includes captives and liberators.

By combining with the be-construction, the noun not only receives a valence structure, but also an event construal which is compatible with the semantics of the be-construction. In other words, the event denoted by the predication is one involving coverage of a location by a theme. For example, beschildern in 52 denotes the activity of placing signs at regular intervals along the bike path. The question that arises here is precisely how we capture the crucial felicity condition identified by Clark and Clark (1979) upon the use of denominal verbs: the source or 'parent' word must denote one thematic role in the situation, while the remaining surface arguments of the denominal denote other roles in that situation. How do we ensure, for example, that the parent 
noun of the verb beschildern, Schild, is taken to be the theme of the coverage event? Our solution, which will be implemented in section 3.8, is to reframe this question by rejecting the assumption that the parent nominal in fact fills the theme role. The parent nominal is not referential, and therefore could not be said to refer to any particular participant in any given event. Instead, we claim, the parent nominal renders the actual theme argument RECOVERABLE, and thereby omissible as per the Oblique-theme construction, which allows null instantiation of theme arguments as discussed in section 3.2. Evidence for this claim comes from the fact that any theme argument whose identity the interpreter might NOT readily recover from the category denoted by the parent noun may be present, as in 54:

4809664:

Die Berkersheimer Grundschule in der Untergasser Hohl wird mit zwei Tafeln beschildert, die in der Straßenverkehrsordnung gar nicht vorgesehen sind.

'The Berkersheim Elementary School on Untergasser Hohl Street will be besigned with two signs that are not even part of the traffic regulations at all.'

A final example of valence creation gives particularly strong evidence in favor of an approach in which both the be-pattern and the Oblique-goal construction are inherently meaningful. These are examples involving nonce verbs, as discussed by Wunderlich (1987: 304). Wunderlich observes that if the nonexisting verb prillen is formed and taken to mean 'hit with a racket' (a meaning that is not otherwise lexicalized in German), the verb can combine with both the Oblique-goal construction and the be-construction:

Sie prillt den Ball auf die Wand.

'She prills the ball onto the wall.'

Sie beprillt die Wand mit dem Ball.

'She be-prills the wall with the ball.'

These examples strongly suggest that it is the skeletal structure of the construction alone, and not any aspect of lexical meaning, that licenses the interpretation of these sentences as involving causation of motion and the particular reading of 55 as involving multiple such events. A plausible account of valence creation requires the recognition of both 'bottom up' contributions to meaning (lexical meaning) and 'top down' contributions to meaning (constructional meaning). The interpretation of denominal verbs like beschildern involves not only the top-down 
imposition of valence structure from the construction but the bottom-up importation of the rich frame semantics of the nominal element with which the construction combines.

3.5. Exteriority. The constructional account of the exteriority constraint discussed in section 2.3.3 with respect to the construal of bewerfen in 23' is straightforward. Rather than appealing to a constraint imposed by the prefix, whose meaning, as discussed in section 2.3.3 would be construction-specific anyway, we view exteriority as constraint on the configuration of the theme element: it must be planar. The claim that this constraint belongs to the construction is substantiated by override effects. Example 23' provides an example of such an override, but perhaps the most cogent example of this phenomenon comes from attested uses of the verb befüllen 'fill'. This applicative verb at first appears to violate the planar-surface constraint in that it necessarily describes an effect upon the INTERIOR of a three-dimensional space. However, we notice that attested uses of befüllen have iterative readings, as in 57-58:

(57) Frankfurter Allgemeine Zeitung, August 7, 1990

Außerdem müßten Betriebe, die Mehrwegflaschen befüllen, eine plötzliche Erhöhung ihrer Pfandrückstellungen bewältigen.

'Moreover companies that be-fill returnable bottles would have to cope with suddenly having to raise their reserve for deposits.'

(58) Süddeutsche Zeitung, July 25, 1994.

Darüber hinaus werden im Jemen 5 Milliarden US-Dollar für eine ErdgasVerflüssigungsanlage bei Aden oder Mukalla fällig, um dort die Tanker nach Japan zu befüllen.

'Moreover 5 billion US dollars will become due for a natural gas liquefaction plant near Aden or Mukalla that serves to fill (lit. be-fill) the tankers to Japan.'

In 57, the iterative reading comes from a construal in which bottles are repeatedly returned and filled. In 58, the iterative reading comes from a construal in which tankers are repeatedly emptied and filled. The iterative reading arises in each case via the override principle 34 , which requires that the filling scene denoted by the verb be reconciled with the planar coverage scene denoted by the construction. The 'compromise construal' is one in which an exterior surface is affected: the iterated filling events, insofar as each occupies a different pair of coordinates, collectively define a planar region over which coverage is effected. Further discussion of the relation of the exteriority constraint to the various senses of the construction will take place in section 4 . 
3.6 Holism. On the account offered here, the source of the holism constraint is the semantics of the be-construction, rather than any general constraint upon the application of predicates to their direct arguments. As discussed in section 2.3.1, we reject Brinkmann's claim that the holism effect can be attributed to Löbner's Presupposition of Indivisibility. There we observed that this principle alone not explain why applicative predications have summative rather than integrative readings. We also depart from Pinker's account of the locative alternation, since we do not attribute the affectedness implication of be-predications to any general principle governing the construal of direct objects. Instead, we view the holism effect as entailed by the situation type denoted by the be-construction: saturation of a surface. The semantics of the be-construction entail coverage of location by theme at a given point in time or over the course of time.

3.7. Concreteness and compositionality. The constructional model is based on the sign: constructions are form-meaning pairs which differ from words only in internal complexity. Like Montague Grammar, Construction Grammar pairs surface structure with a semantic representation; no 'deep' level of semantic representation intervenes between these two levels. Thus, the constructional model does not rely on either lexico-semantic 'transformations' or multiple types of semantic representation (like those representations which are input to Lcommand and functional application in the Brinkmann-Wunderlich model). In addition, the constructional model does not rely upon abstract (phonologically null) elements; denominal verbs, for example, are not represented as arguments of phonologically unrealized verbs but as nominals which assume valence structures by virtue of unification with argument-structure constructions. The constructional model is concrete, and therefore conforms well to Jackendoff's Grammatical Constraint - a constraint on semantics which, in Jackendoff's words, 'serve(s) to make semantic theory responsible to the facts of grammar' (1983: 18). Since syntax encodes propositions related to events and states of affairs, we must assume that it does this in an efficient and relatively transparent way. It therefore makes sense to base syntactic theory on the assumption that argument-structure patterns directly express basic-level scenes.

But in attributing meaning to syntactic patterns in the interest of concreteness, we potentially undermine the fundamental purpose of syntactic theory: to describe sentence meaning compositionally. If the conceptual content of a sentence now comes not only from lexical conceptual structures but also from the syntactic patterns that contain those lexical items, we sacrifice a constrained model of semantic composition. Like Jackendoff, we question the assumption that this model must necessarily be preserved. As Jackendoff observes:

[A] more constrained theory is only as good as the empirical evidence for it. If elevated to the level of dogma (or reduced to the level of presupposition) so that 
no empirical evidence can be brought to bear on it, then it is not being treated scientifically. (1997a: 50)

Jackendoff's response is a reminder that the empirical criteria must take precedence over the theory-internal criterion of parsimony. But we have an additional response, which Jackendoff, an advocate of enriched composition but not of a construction-based syntax, does not give: the constructional model is in fact compositional, although not in the standard sense. If the meaning of a sentence is the result of integration of verbal and constructional semantics in accordance with the override principle of 34 then that meaning results from semantic composition. In other words, we do not abandon a constrained theory of sentence meaning by acknowledging the existence of 'top down' or constructional meaning. The mechanism of unification ensures that sentence meaning is the result of constrained combination of symbolic structures.

3.8 The formal representation of the applicative pattern. In this section, we will give only a brief sketch of the applicative construction and the manner in which it combines with other independently motivated constructions to license applicative sentences. A detailed treatment of the model being described here can be found in Michaelis \& Ruppenhofer (in press: ch. 4). This model, which is based upon unification, is sufficiently straightforward to permit an intuitive explanation here. Unification of constructions can best be described in terms of a metaphor involving the superimposition of slides. Any slide (construction) can be superimposed upon any other as long as the semantic and syntactic specifications on each slide show through' - that is, provided there is no conflict among the specifications on the slides in the stack. All linking constructions operate upon the valence set specified by a given lexical item. The number of valence elements specified by a given linking construction may be greater or less than the number of valence elements specified by the lexical verb.

One can think of the linking constructions as being superimposed in sequence upon a given verb's lexical entry (although in reality the interacting constructions apply simultaneously). The lexical entry contains a minimal valence, i.e., an array of thematic roles, whose grammatical expression is determined by the linking construction or constructions applied. A minimal lexical entry which is unified with linking constructions is said to be a fully specified lexical entry: one in which every thematic role supplied by the lexical entry is linked with a grammatical function. We depart from the Fillmore \& Kay account of argument-structure unification only in one regard: we allow the override of the syntactic category of an open-class lexical item for cases in which nouns and adjectives unify with the Applicative construction, a verb-headed construction. This move seems to be the only way that we can capture the observed form-class fluidity without resorting to the assumption of unconstrained polysemy which was criticized in section 3.1. 
Linking in the Fillmore \& Kay account is incremental, in the sense that each linking construction determines the grammatical function of only a single theta role, although all unifying linking constructions will denote the same event type and thereby have identical theta grids (e.g., the trivalent theta grid associated with transfer). Thus, the Applicative construction merely constrains the syntactic realization of the locative thematic role. As described by Michaelis \& Ruppenhofer (in press: ch. 4), the grammatical realization of the remaining thematic role or roles will be determined by those constructions with which the be-construction combines, including the Passive, Active, Subject and Oblique-theme constructions. Figure 1 shows the bivalent version of the $b$-construction. Figure 2 shows the trivalent version. ${ }^{12}$

\section{Figure 1 about here: The Applicative, bivalent type}

\section{Figure 2 about here: The Applicative, trivalent type}

As shown in Figure 2, the trivalent pattern denotes a causative event involving a placeable object. This event may be telic (as in the case of an accomplishment construal) or atelic (as in the case of an activity construal). This analysis of caused change of location differs from those advocated by, e.g., Rappaport Hovav \& Levin (1998) and Hale \& Keyser (1993). These authors assume that such causative events entail a change of state in which the theme remains at the location as the culmination of the event. As we will show in section 4.1, however, trivalent applicative predications may be used in situations in which the objects moved do not remain at the location state, and in which the location is accordingly unchanged.

The bivalent Applicative construction has an even greater degree of aspecutal neutrality than the trivalent version of the construction. As shown in Figure 1, the situation type denoted by the bivalent pattern is underspecified with respect to the static-dynamic contrast, since bivalent applicative predications may either denote states or events. The underspecification of aspectual information in these two constructions reflects the fact that, as we will see in section 4 , the coverage schema expressed by each is compatible with stative, processual (activity) and accomplishment construals. Thus, the transitivity of the argument-structure pattern entails nothing about telicity or even perfectivity. This is a position which will be defended more thoroughly in section 4.1. ${ }^{13}$

We postulate that the two versions of the Applicative construction are related via an INHERITANCE LINK. Inheritance networks, as per Lakoff (1987), Goldberg (1995), Michaelis \& Lambrecht (1996), and Jackendoff (1997b) are used to capture relationships between linguistic signs when these relationships are not sufficiently productive to be represented as rules, but are nevertheless entrenched connections within an associative memory. The inheritance model is 
similar to that described by Pinker \& Prince (1991: 232) as the connectionist model of memory. This model is 'both associative and superpositional: individual [linguistic] items are dissolved into sets of features, and similar items...overlap in their physical representations, sharing representation real estate'. In accordance with the CG tradition as established by Lakoff and Goldberg, among others, we will represent these overlap relations in terms of links in a hierarchical network, where a dominated construction inherits all nonconflicting specifications from the dominating construction. In the case of the two versions of the Applicative construction, we propose that the bivalent version is related to the trivalent version by means of what Goldberg and Michaelis \& Lambrecht call a SUBPART LINK: the trivalent construction subsumes the semantic representation and syntactic (linking) constraints of the bivalent construction.

The analysis of trivalent $b e$-predications involves the OBLIQUE-THEME construction, given in Figure 3:

\section{Figure 3 about here: The Oblique-Theme Construction}

The Oblique-Theme construction has as its semantic value an event type in which an agent causes a theme to cover a location (the goal). Although we have not shown the relevant unification indices, the agent, theme and goal of this event type will unify with those same thematic roles in the valence set of the lexical verb. The event type denoted by the ObliqueTheme construction is identical to that denoted by the trivalent applicative construction, ensuring unification between the two constructions. The only linking constraint imposed by the ObliqueTheme construction is this: the theme argument links to the oblique grammatical function, which is realized either as a prepositional phrase headed by mit or as a null (pragmatically recoverable) complement. We have said nothing in the statement of the Oblique-Theme construction about the construal of the theme as nonindividuated. We have chosen to remain agnostic concerning the appropriate representation of the nonindividuated construal, since it is a potential rather than a requirement. As Brinkmann and others have observed, an individuated construal of the theme is compatible with applicative semantics, as in Erna bekochte zehn Männe mit einem einzegen Truthan ('Erna be-cooked ten men with a single turkey').

The Oblique-Theme construction unifies with denominal applicative verbs like behaaren, as in 1, or beschildern, as in 52. Here, the identity of theme argument can be reconstructed on the basis of the semantics of the lexical form with which the various linking constructions unify. This lexical form is a nominal; it is only by virtue of unifying with an argument-structure construction - in this case the trivalent applicative construction - that the nominal receives a theta frame. In accordance with the Gricean principle of omission up to recoverability (modulo 
constructional constraints), a theme argument which is not recoverable from the type denoted by the verb, owing to the greater specificity of that theme argument, will be syntactically realized, as in the English example He soled my shoes with gum soles and the German example given in 54.

Our model of the interaction between a verb and a given version of the Applicative construction, bivalent or trivalent, relies upon the distinct manner in which verbs and constructions ensure realization thematic structure. In short, verbs rely upon constructions in ways that constructions do not rely upon verbs. For the verb, realization of thematic structure means ensuring syntactic expression of each subcategorized argument through fusion: each role licensed by the verb must be identified with a role licensed by a linking construction. For the construction, adherence realization of thematic structure means ensuring syntactic expression of each argument, whether or not that argument fuses with an argument licensed by the verb. What this means is that the construction's arguments may be expressed by maximal categories (e.g., NP) which are not part of the subcategorization frame of the verb. For the bivalent applicative construction, this situation is exemplified by predications containing bemogeln ('cheat'): the 'malefactee' argument is contributed by the construction in Figure 1. This construction also constrains the grammatical function which can be assigned to this role: it must be either subject or object (to be determined by which of the two voice constructions, Passive of Active, unifies with this one). For the trivalent applicative construction, verbal-valence augmentation is exemplified by the verb bebauen ('build up'). As a verb of creation, bauen licenses two arguments, agent and theme. The construction both adds a goal (location) argument to the verbal valence set and restricts the grammatical function to which the location argument can be linked, as described above. Whenever the valence set licensed by the construction properly includes that licensed by the verb, the verb bears a means relation to the event type denoted by the construction. ${ }^{14}$

The PRED variable in Figures 1-2 is used in accordance with Goldberg (1995) to represent the open-class element with which the construction unifies. The angled brackets to the right of the PRED variable represent the theta frame licensed by the open-class element. As described in section 3.4, the open-class element with which the be-construction unifies may not be an inherently relational element, and thereby lack argument structure. For example, the open-class element may be a noun, as in the case of beschildern 'put up traffic signs' and besohlen 'sole, as of a shoe'. As we argued in that section, appropriate thematic elements can be found in the rich background knowledge with which the particular word is associated. This semantic frame contains participant roles, and these are the roles which will be 'plugged into' the argument set associated with the filler of the PRED variable. In the case of the verb besohlen, for example, this set will contain the cobbler, the sole and the shoe. These frame-specific roles are required to fuse with the more schematic argument roles licensed by the be-construction. For this reason, we 
assume that denominal verbs necessarily have an elaboration relationship to the applicative construction.

The Oblique-Theme construction has as its semantic value an event type in which an agent causes a theme to cover a location (the goal). Although we have not shown the relevant unification indices, the agent, theme and goal of this event type will unify with those same thematic roles in the valence set of the lexical verb. The event type denoted by the ObliqueTheme construction is identical to that denoted by the trivalent applicative construction, ensuring unification between the two constructions. The only linking constraint imposed by the ObliqueTheme construction is this: the theme argument links to the oblique grammatical function, which is realized either as a prepositional phrase headed by mit or as a null (pragmatically recoverable) complement. We have said nothing in the statement of the Oblique-Theme construction about the construal of the theme as nonindividuated. We have chosen to remain agnostic concerning the appropriate representation of the nonindividuated construal, since it is a potential rather than a requirement. As Brinkmann and others have observed, an individuated construal of the theme is compatible with applicative semantics, as in Erna bekochte zehn Männe mit einem einzegen Truthan ('Erna be-cooked ten men with a single turkey').

\section{The Semantics of the Applicative Pattern}

Like Brinkmann, we argue that be-verbs form a coherent semantic category. However, under our account this semantic coherence does not arise from the interaction of syntactic and general semantico-pragmatic principles. Rather it is seen as a reflection of the polysemy structure associated with the applicative construction. In accordance with Goldberg's (1995) analysis of the English ditransitive and other argument-structure patterns, we postulate that the meanings of the be-pattern are related via independently motivated patterns of semantic extension, and represent a radial category of senses. As in Lakoff's (1987) description of radial-category structure in classifier systems, the polysemy structure at issue here allows for the cancellation of implications associated with the central sense. We will see that certain senses invoke components of the coverage scenario, like transfer, without entailing coverage. We will also see an example of chaining within the network: one extended sense shares semantic content with another extended sense but not clearly with the central sense.

The exposition of senses associated with the applicative pattern will focus upon specific (and in many cases partially overlapping) classes of verbs (e.g., verbs denoting iterated activity). A question that arises is how this mode of description can be reconciled with our central contention-that the semantic effects which distinguish be-predications from their paraphrases 
are attributable to the semantics of the applicative pattern rather than to the semantics of a particular set of verbs. In other words, if we view the meanings of be-predications as the products of a reconciliation procedure whereby the meaning of the verb is brought into conformity with the meaning of the construction, how can we also treat the be-verbs as 'stored', i.e., listed, elements? The answer to this question requires us to reject a principle which Langacker (1987) has called the RULE-LIST FALLACY. Langacker applies this term to the (typically implicit) principle which holds that complex structures that can be modeled by an online process cannot also be viewed as stored.

In a broader sense, certain work on Gricean inference (Morgan 1978, Hinkelman \& Allen 1989) can be viewed as undermining the rule-list distinction: while Gricean inferences are readily modeled as algorithms, certain Gricean inferences, in particular those associated with indirect speech acts, may conventionally attach to certain forms (a phenomenon which Morgan refers to as 'short-circuited' conversational implicature). With regard to morphology in particular, Bybee (1995) rejects the idea that the products of regular morphology are exclusively generated online. On the basis of experimental work by Losiewicz (1992), Bybee argues that high-frequency regular past-tense forms are stored in the lexicon. By the same token, we view high-frequency beverbs as clustering in narrowly defined lexical classes that reflect the (conventionalized) patterns of semantic extension observed for the applicative construction. However, we simultaneously maintain that the interpretation of be-predications involves the integration of constructional meaning and verb meaning. Were this not so, productive uses of the applicative pattern could not plausibly be modeled (see section 3.4 for argumentation on this point).

The discussion will proceed as follows. In section 4.1, the central sense will be described. In section 4.2, we will describe three classes of be-predications which involve metaphorical extensions of this basic meaning. In section 4.3, we will look at five classes of be-predications whose meanings relate to the central sense via various inductive inferences. In section 4.4, we will consider the relationship of this semantic analysis to a diachronic analysis of the be-pattern given by Ruppenhofer (1999). In particular, we will consider the relationship between the meaning of the be-pattern as we have described it and earlier uses of the be-prefix to denote SURROUNDING/CONTAINMENT and PROXIMITY.

This exposition of the usages of the applicative pattern requires a disclaimer: the order of presentation of the verb classes (that is, the usages of the construction) is not intended to reflect any avenue of development of these senses. Instead, we view each sense extension as exploiting a semantic potential inherent in the semantic schema which represents the core sense; no extended sense is viewed as dependent on any other. While there is evidence (to be discussed in section 4.4) which suggests the historical primacy of the coverage sense of the pattern, we cannot on the basis of this evidence propose a relative chronology of the extended senses. Further, we do not 
intend to suggest that metaphorical extensions of the applicative pattern are recent innovations. Metaphorical extensions, like the use of the applicative pattern to describe thorough discussion of a topic, are old. This semantic extension seems to be at least as old as Middle High German, as suggested by a look at the entries for bereden 'discuss', besprechen 'discuss', beklagen 'complain, mourn', besehen 'look at, examine', beschauen 'look at, examine', beschreiben 'describe', besingen 'sing about, of', and bedenken 'think about, reflect on' in Lexer's (1872) Middle High German dictionary and in the available installments of the Early Modern High German dictionary (Ulrich \& Reichmann 1999). ${ }^{15}$ The radial model of senses which we will offer, in which each sense of the pattern overlaps semantically with the core sense, is consistent with the diachronic facts and provides a plausible model of what might make the various senses cohere synchronically. Figure 4 shows the associative network of meanings which will be discussed in the forthcoming subsections.

\section{Figure 4 about here: The meanings of the applicative pattern}

4.1. The prototype. The conceptual archetype with which the applicative pattern is associated is a scene in which a THEME COVERS A SURFACE ${ }^{16}$ This scene is denoted by bivalent verbs like befahren in 59 and entailed by trivalent verbs like beschmieren in 60:

MK1/MHE.00000, HEUSS, ERINNERUNGEN 1905-1933, Memoiren

Nun hatte ich wohl die Ostsee befahren und die Nordsee geschmeckt, aber das 'Schwäbische Meer', wie man in meiner Jugend den Bodensee nannte - die Formel ist verdorrt -, war mir fremd geblieben.

'True, I had sailed around (lit. be-driven) the Baltic Sea and I had had a taste of the North Sea, but the "Swabian Sea", as people called the Bodensee in my youth—-the phrase has withered away since—-had remained unfamiliar to me.'

36713673

Jugendliche Straftäter würden bewußt Sitze zerstören, Fenster heraustreten, Wandverkleidungen beschmieren oder von den Wänden reißen

'Youth offenders would purposely destroy seats, kick out windows, smear (lit. be-smear) wall coverings or tear them off the walls.'

Sentence 60 entails that significant portions of each wall hanging are smeared while 59 describes extensive travel over the Baltic Sea. However, the notion of saturation at stake here does not require that an entire surface is covered: some parts of each wall hanging may have been 
spared and areas of the Baltic Sea may not have been reached. Moreover, while the location may often be affected in the sense that it undergoes a noticeable change of state, this is not a necessary consequence of saturation: the Baltic Sea is not changed by the sailor's travels in 59. Finally, notice that saturation may be summed over time, since, for example, the sailor can only occupy a single location at any given time. The type of construal is equivalent to SUMMARY SCANNING, a mode of cognitive processing in which co-activation of scanning events produces a coherent gestalt (Langacker 1987: 144-45). In the case of the sailing activity the individual scanning events establish distinctness of sailor and water surface and track the change in relative position. If all the scanning events are overlaid at once (in the way transparencies can be overlaid), there will be only one water surface but many positions occupied by the sailor. This overlay configuration is identical to the coverage schema denoted by the applicative construction.

Notice that while we have used the terms configuration, schema, scene and archetype in this section to describe the saturation constraint, we have not referred to an event type. This may appear puzzling, since the constructional model of argument structure upon which we base this analysis is one in which argument-structure patterns denote basic-level event structures. We have avoided the term event structure or event type here because these terms suggest that the coverage schema can be characterized as belonging to a particular aspectual class. Coverage is a topological notion, and has no temporal dimension. Accordingly, the saturation constraint may be satisfied by both perfective and imperfective predications. In 61, for example, a be-predication containing the stative verb bewohnen ('inhabit') denotes a situation of coverage which holds at a single point in time:

MMM/102.37001: Mannheimer Morgen, 09.02.1991, Leserbriefe;

Die alteingesessenen Altriper, die den Ortskern bis jetzt noch bewohnen, werden sich eben mit dem noch stärker werdenden Durchgangsverkehr abfinden müssen.

'The long-time Altriperians who up until now are still living in (lit. be-living) the town center will just have to get used to the increasing through traffic.'

The coverage concept associated with bewohnen is also compatible with a habitual construal, in which a single inhabitant effects coverage of a given location over time 62a. As shown in 62b, a bewohnen predication is anomalous when the location (in this case, a city) is too large to allow an individual to effect coverage over time; the prepositional paraphrase in $62 \mathrm{c}$ is, however acceptable, as the coverage constraint is not operative here:

(62) a. Ekkehard bewohnt ein Apartment in Berlin. 
'Ekkehard be-lives an apartment in Berlin.'
b. *Ekkehard bewohnt Berlin.
'Ekkehard be-lives Berlin.'
c. Ekkehard wohnt in Berlin.
'Ekkehard lives in Berlin.'

Within the class of perfective applicatives, both accomplishment and processual (activity) readings are attested. These two readings are closely aligned semantically, since accomplishments entail processes. Nonpunctual perfective verbs (e.g., walk) typically have both activity and accomplishment readings, and the same can be said of bivalent applicative sentences like 59, which have both telic and atelic readings. If the interpreter views the sailing activity as having culminated in thorough coverage of the body of water by the sailor's craft, the predication denotes an accomplishment. If instead the interpreter construes the sailing activity as a set of subevents with no inherent point of culmination, the predication denotes an activity (as expressed by the processual gloss 'sail around'). Because these two readings are available, both types of durational adverbials are licensed, as shown in 63:

$$
\begin{aligned}
& \text { Sie besegelten die Karibik }\left\{\begin{array}{l}
\text { in drei Monate } \\
\text { drei Monate lang }
\end{array}\right\} . \\
& \text { 'They sailed the Carribean }\left\{\begin{array}{l}
\text { in three months } \\
\text { for three months }
\end{array}\right\} . '
\end{aligned}
$$

Since bivalent applicatives denote both processual and static situations, the coverage schema in our framework cannot be equated with the concept of an incrementally interpreted location argument. Trivalent applicative predications, which are necessarily perfective, generally have accomplishment readings, as in 64:

$$
\begin{gathered}
\text { Sie belud den Wagen }\left\{\begin{array}{l}
\text { in drei Stunden } \\
* \text { drei Stunden lang }
\end{array}\right\} \\
\text { 'She loaded the wagon }\left\{\begin{array}{l}
\text { in three hours } \\
* \text { for three hours }
\end{array}\right\}
\end{gathered}
$$

In such cases our analysis overlaps with Brinkmann's analysis (as described in section 2.3.2): the location argument is incremental in the sense of Dowty (1990), since its 'exhaustion' determines the time course of the event. However, trivalent applicative predications do not always require telic construals and do not always permit them. The telic construal appears to be required only when the base verb is telic (contingent upon a bounded construal of the object- 
denotatum), as in the case of laden. The trivalent applicative predication in 65, which contains the atelic base verb werfen ('throw'), does not have a telic interpretation:

$$
\begin{gathered}
\text { Sicherheitskräfte wurden mit Steinen beworfen }\left\{\begin{array}{l}
* \text { in drei Stunden } \\
\text { drei Stunden lang }
\end{array}\right\} \\
\text { 'Security forces were pelted with stones }\left\{\begin{array}{l}
*_{\text {in three hours }} \\
\text { for three hours }
\end{array}\right\}
\end{gathered}
$$

Numerous acts of transfer occur in the course of the event denoted by 65 , and yet there is no point at which transfer is complete. Thus, while the trivalent applicative construction denotes a transfer event, insofar as an agent causes a theme to move to a location, this event type has both telic and atelic instantiations. Accordingly, the term transfer event, like the term coverage, should not be taken to entail that an endpoint is reached. The trivalent applicative construction is unmarked with respect to telicity, and only predicate-argument structure fixes aspectual class. In proposing that the applicative pattern is aspectually neutral, we counter the recent analytic trend toward viewing argument-structure variation as aspectually driven (Rappaport Hovav \& Levin 1998). Since numerous other linking constructions are aspectually neutral, e.g., the transitive and passive constructions, we feel it is appropriate to regard aspectual variability and valence variability as reflecting related but orthogonal categories of event structure.

As pointed out earlier, entailments shared by two situation types may be manifested in common morphosyntactic coding. Transfer has cognate concept, removal, which is expressed by the trivalent applicative pattern as well. In the case of transfer and removal, the shared entailment is causation of change of location, and languages like Latin appear to neutralize the direction of transfer, coding the two event types identically. For example, trivalent verbs like compleo ('fill') and privo ('strip') license the same case frame, with the possibility of either ablative or genitive coding for the oblique theme argument (Michaelis 1993). In German, removal verbs coded by the applicative pattern typically denote robbing, e.g., bemopsen, berauben, and beklauen. An example involving beklauen is given in 66:

36891726

Allein die Gelnhäuser Stadthalle habe das Trio zweimal beklaut, berichtete ein Kriposprecher am Donnerstag .

'A police spokesman reported on Thursday that the trio robbed (be-robbed) the Gelnhausen City Hall twice.' 
Like the trivalent $b e$-predications denoting coverage, $b e$-predications denoting removal can be said to denote a salient effect upon the location argument. However, applicative verbs of removal differ from applicative verbs of coverage in that the former form a small class with idiosyncratic properties. For example, applicative verbs of removal do not typically license an obliquely expressed theme argument. Compare 67, which contains the nonapplicative verb klauen ('steal'), with 68, an ill-formed variant of 67 in which the theme argument is expressed:

(67) Allein aus/von der Gelnhäuser Stadthalle habe das Trio zweimal Geld geklaut, berichtete ein Kriposprecher am Donnerstag.

'A police spokesman reported on Thursday that the trio stole money from the Gelnhausen City Hall twice.'

(68) *Allein die Gelnhäuser Stadthalle habe das Trio zweimal um 1000 Mark beklaut, berichtete ein Kriposprecher am Donnerstag .

'A police spokesman reported on Thursday that the trio robbed the Gelnhausen City Hall of 1000 marks twice.'

In 68, we use a preposition phrase headed by um ('around') to express the oblique theme (rather than, e.g., a PP headed by von 'of' or mit 'with') on analogy with the applicative verb betrïgen ('cheat'). This verb, although arguably a verb of removal, does license an $u m$-headed PP denoting the theme (the item which the victim loses to the cheater). Neither this fact about betrügen nor the more general theme-coding constraint exemplified in 68 follows from anything that we know about removal. That small verb clusters like the removal class should behave idiosyncratically is expected under Goldberg's (1995) model of partial productivity. Goldberg suggests (p. 132) that the association between a given construction and a given verb from a low-productivity class may be learned as an idiom.

4.2. Metaphorical extensions of the central sense. The coverage schema associated with the basic usage of the applicative pattern is compatible not only with concrete physical situations but also abstract ones. Langacker (1991) describes the basis of such semantic broadening as follows: "Extensions from the prototype occur...because of our proclivity for interpreting the new or less familiar with reference to what is already well established; and from the pressure of adapting a limited inventory of conventional units to the unending, ever-varying parade of situations requiring linguistic expression" (p. 295). Various metaphorical links allow the use of the coverage schema in the domains of speech, perception, and attention. In accordance 
with Lakoff's (1990) Invariance Hypothesis, by which ontological components of a basic-level semantic schemata are conserved by metaphorical extensions of that schema, we can observe that these metaphorical mappings replicate the thematic and linking structure associated with the bivalent applicative construction. We treat these metaphorical usages as distinct (conventionalized) senses of the be-pattern because otherwise there would be no way of predicting which theoretically eligible metaphors would be expressed by the be-pattern and which would not. In the following three subsections, we describe three metaphorical extensions.

4.2.1. Seeing is contact with the percept. One's gaze goes from one's eyes to what one sees. One sees whatever one's gazes touches (Lakoff 1987:437). These metaphors underlie German usages like the following:

(69) Sie konnte ihre Augen nicht von ihm nehmen.

'She wasn't able to take her eyes off him.'

(70) Er richtete seinen Blick auf das Buch.

'He turned [directed] his eyes to the book.'

(71) GR1/TL1.12150 Weyden, C.: Träume sind wie der Wind. Hamburg 'Ich hoffe es.' Und wieder ging sein Blick zu dem anderen Tisch hinüber.

“ "I hope so". And another glance went over to the other table.'

Verbs, prepositions, and particles that are used to designate a trajector's movement to a physical object can be extended metaphorically to designate a metaphorical trajector's movement across the field of vision (cast a stone at - cast a glance at; point a weapon at - point one's eyes at). According to this model, INSPECTION of a percept is thorough coverage of the percept by the perceiver. In $b e$-predications that denote vision, the eyes are construed as a theme moving over the percept. The following be-predications instantiate this particular conception:

BZK/W59.00790, WE 07.09.59, S.06, LESERBRIEFE

Niemand sollte sich den Gang zum alten Museum ersparen. Man muß einmal Zeit genug haben, den Isenheimer Altar des Meisters Matthies zu beschauen, den ganzen Riesenaufbau in all seiner Wucht und Farbentiefe.

'Nobody should avoid the walk to the old museum. For once, one has to spend enough time to examine (lit. be-look) the Isenheimer altar of master Matthies, the whole gigantic body in all its massiveness and depth of color.' 
(73) MK1/LFH.00000, FRISCH, HOMO FABER, Roman. Suhrkamp

Später auf Deck äußerte Sabeth (ohne Drängen meinerseits) den Wunsch, einmal den Maschinenraum zu besichtigen, und zwar mit mir [...]

'Later on deck Sabeth expressed the wish (without me urging her) to tour (lit. be-sight) the engine-room, and to do so with me [...]'

Although one might presume from the description of the metaphor that the agent maps to the perceiver and the theme to the gaze, the two roles are not obviously distinct, and we have found no be-predications in which the gaze/theme maps to an oblique expression. Insofar as the perceiver is difficult to separate from his or her perception, the agent and theme roles appear to conflate, and only the bivalent be-pattern is involved. The verbs in 72-73 have an instance relation to the applicative construction, since the perceiver and percept arguments map to theme and location, respectively. The joint fusion of the perceiver and the means of perception with the theme argument is a general characteristic of examples involving perception, including those which involve coverage of the percept via other sensory modalities, e.g., olfaction, as in 74 :

(74)<6vdjTb12mnB@sampo.han.de>

Als Nichtraucher behaupte ich, daß sie nicht "stinken". Immerhin hatte ich auch schon Gelegenheit, Raucherinnen aus ziemlicher Nähe beriechen zu können. Ergebnis: sie stinken nicht.

"As a [male] non-smoker I say that they [smokers] do not "stink". At least, I have had the opportunity to be-sniff female smokers from rather close distance. Conclusion: they don't stink.'

4.2.2. Attending to something is directing one's attention to it. Conventional examples of this metaphor are given in (75-77):

(75) Er richtete seine Gedanken auf das Thema.

'He directed his thoughts to the topic.'

(76) Seine Gedanken schweiften ab.

'His thoughts went astray.'

(77) Wohin gehen Ihre Überlegungen?

'What are you thinking of (lit. Where are your thoughts going to)?' 
Via this metaphor, tracking or monitoring a percept can be viewed as maintaining contact with it across a set of space-time coordinates, where the emergent configuration involves coverage of the region defined by that cluster of points. This conception underlies bivalent denominal bepredications like the following, in which, as in the vision case in 4.2.1, the cognizer and the cognizer's focus of attention are conflated and jointly fuse with the role of theme:

(78) Der Polizist beobachtete den Verdächtigen.

'The policeman watched (lit. be-observationed) the suspect.'

(79) Peter muß seine kleine Schwester beaufsichtigen, wenn seine Eltern zur Arbeit sind.

'Peter has to look after (lit. be-supervision) his little sister when his parents are at work.'

(80) Peter hat den Unfall verursacht, weil er die Vorfahrt nicht beachtete.

'Peter caused the accident because he didn't pay attention to (lit. be-attention) the right of way.'

5.2.3. Discourse is travel across a topic. Other be-predications express metaphorical mappings via the TRAVEL METAPHOR: mental activity and conversation are both movement through some metaphorical space, the space being identified with the subject-matter of thought or speech (Sweetser 1987, 1990). We find this travel metaphor in German usages like 91:

(81) Auf dieses Thema müssen wir noch einmal zurückkommen.

'We will have to come back to this topic.'

In these metaphorical usages we find verbs, particles, and prepositions extended from their original domain of physical movement to the domain of movement in speech or thought. Such metaphorical situations may be expressed by be-predications when the saturation implication is prominent, i.e. when the theme (the conversant) covers the location (the topic) comprehensively. Compare sentence 82, which describes a serious discussion, to sentence 83, which describes the conversational efforts of two previously unacquainted people on a first date: 
(82) R1/TL1.09008 de Groot, B.: Dein Vater wird uns liebgewinnen.

Nebenan befand sich Olga Gorenkamps Nähzimmer, die Tür war nur angelehnt. Jetzt besprachen sie eingehend die neue Situation. Und sie war äußerst günstig für das Weingut.

'Next door was Olga Glorenkamp's sewing room. The door was ajar. Now they were discussing (lit. be-speaking) the new situation thoroughly. And it was extremely favorable for the winery.'

\section{MK1/LJA.00000, JOHNSON, DAS DRITTE BUCH ÜBER ACHIM}

Karsch sagte ja. Er war erstaunt, daß sie gebeten hatte. Sie verabredeten sich für einen Abend, an dem ein Fubballspiel viele Fahrzeuge aus der Umgebung heranholen und dann wieder auf die Autobahn schicken würde, sie trafen sich vor dem Theater, sprachen über die Unterschiede der beiden deutschen Strabenbilder, fuhren los.

'Karsch said yes. He was surprised that she had asked. They made an appointment for an evening when a soccer game would attract a lot of cars from the surrounding area and send them back on the highway later. They met in front of the theater, spoke about how different the street looked in the two Germanies, and then drove off.'

The relationship between thorough discussion and coverage of a surface is evident a well in the English contrast between talking something over and talking about something.

4.3. Other extensions of the central sense. In addition to the metaphorical uses of the central senses discussed in 4.2. there are extensions of the central senses in which the coverage semantics is either missing or of secondary importance. The majority of these extensions appear to be the result of pragmatic inferences like those described by Hopper \& Traugott's (1993) as examples of PRAGMATIC STRENGTHENING, a metonymic inference mode by which a semanticopragmatic 'side effect' of some signification is elevated to the level of a distinct meaning, which may lack entailements of the source meaning (see also König \& Traugott 1988). An example of pragmatic strengthening is the development of concessive or adversative markers from markers of temporal persistence like still; the newly developed marker is usable in perfective predications, where no temporal continuation is implied, as in She still got angry (König \& Traugott 1982). In the following four subsections, we will describe four meanings of the be-pattern which appear to involve this metonymic mode of inference: transfer, iteration, intensification, and affectedness. A 
fifth subsection will consider a class of denominal be-verbs expressing social roles, which appear to involve the affectedness meaning.

The first class of cases, that of applicatives denoting transfer (4.3.1), deserves comment here because it is subject to dual categorizations: it is both a metaphorically based extension and an inference-based one. Since this class involves a metaphorical extension, thematic structure is isomorphic to that of the applicative construction, as in the metaphorically based extensions discussed in section 4.2. As per the Invariance Hypothesis, predications which denote metaphorical transfer preserve the thematic and linking constraints associated with the (trivalent) applicative construction: they entail an agent, a nonoblique goal and a (canonically nullinstantiated) theme. However, this metaphorical extension is based upon a prototypical rather than necessary component of the coverage schema: transfer. For this reason, the coverage entailment which plays a role in other metaphorical uses of the applicative pattern plays no role here. The remaining pragmatically based extensions discussed in this section are nonmetaphorical. They are based solely on marginal implications of the applicative pattern, and do not partake directly of the semantics of location or transfer. These extensions thereby lack the thematic and linking constraints associated with the applicative pattern. These extensions meet only the valency and morphological conditions on applicatives: they are bivalent and thereby compatible with the transitive linking construction described in Michaelis \& Ruppenhofer (in press).

4.3.1. Communication and affecting as transfer. Applicative predications may describe situations in which metaphorical objects are transferred to a goal or recipient. This sense can be viewed as an extension of the meaning of the trivalent be-pattern, in which saturation comes about through transfer of a concrete theme onto a location, e.g., behängen 'be-hang', beladen 'beload', bedecken 'be-cover'. In its metaphorical transfer sense, however, the be-construction does not entail saturation; transfer is the sole entailment. One kind of metaphorical theme is an idea. Via the IDEAS ARE TRANSFERABLE OBJECTS metaphor and the CONDUIT metaphor of communication (Reddy 1979), the be-construction can be used to describe communicative events. The agent is a person delivering the idea, the idea is the theme, and the recipient is the goal. The be-construction evokes this metaphor in the following denominal example:

Message ID <22D3C5E8H000002AFH@p-alv.wds.mcnet.de>

Er hatte niemals daran gedacht, sie $\mathrm{zu}$ fragen oder sie auch nur zu benachrichtigen, daß er Clarisse für verschwunden hielt.

'He had never remembered to ask her or to even inform her (lit. be-news) her that he considered Clarisse to have disappeared.' 
The metaphor can be made explicit in the sentence's paraphrase: ... oder ihnen auch nur Nachricht darüber zu geben, daß er lit. ' $\ldots$ or to just give them news about the fact that he ...'

It also occurs independently of situations which can be described by be-predications in such usages as:

\section{Er sandte mir einen Gruß.}

'He sent me greetings.'

Another metaphorical link to the domain of transfer is provided by the EFFECTS ARE TRANSFERRED OBJECTS metaphor (Goldberg 1995: ch. 6). The use of the be-construction to express this metaphor may be seen as doubly motivated: first by the fact that literal uses of the (trivalent) applicative pattern involve transfer and second by the fact that coverage of a location often involves an effect upon that location. Consider the following denominal example:

WKB/TZ1.00567, taz (Sonderheft 1 und 2), Nach Polen und Ungarn ...

Versuchte die Partei mit ihrem anfänglichen unverbindlichen Dialogangebot vergeblich den demonstrativen Unmut der Bevölkerung einzudämmen, so hofft sie jetzt, die Konflikte am runden Tisch zu kanalisieren und das Volk zu befrieden.

'If the party tried in vain to contain the ostentatious ill humor of the population with their initially non-binding offer of a dialog, it is now hoping to channel the conflicts at the round table and to bring peace to (lit. be-peace) the people.'

In this example, the source nominal (Fried) denotes a transferable effect. Transferable effects include properties, as expressed by deadjectival applicative predications like 88 (=6):

(88) Süddeutsche Zeitung, March 4, 1996

Deutsche Grenzschützer befreiten die Geiseln am 18. Oktober 1977 in Mogadischu; Andrawes überlebte als einziger der Terroristen.

'Members of the German border patrol freed (lit. be-freed) the hostages on October 18, 1977 in Mogadishu; Andrawes was the only one of the terrorists to survive.' 
These denominal and deadjectival applicative verbs lack base forms. Therefore, it is plausible to assume that their meanings come from the integration of constructional and lexical semantics via the elaboration relation, in much the same way that a transfer implication attaches to denominal applicatives which express coverage of a surface, e.g., behaaren ('be-hair') and beschildern ('besignpost'). In both the literal (coverage) cases and the metaphorical cases in 87-88, the lexical item which unifies with the construction is construed as a transfer verb via the override principle, and the oblique theme is null instantiated owing to its recoverability. The examples in 89-90 show that the transfer of abstract effects is a special case of a general model in which effects of all kinds, including physical ones, are transferable from an agent onto a patient-goal:

Message ID <782aug\$gr5\$1@infosun2.rus.uni-stuttgart.de>

Jeder will dem Gegner so schnell wie möglich eine tiefe blutende Wunde beibringen, ihn 'abstechen', wie es im Jargon der schlagenden Verbindungen heißt 'Each wants to inflict on the opponent a deep bleeding wound (lit. bring the opponent a deep bleeding wound) as fast he can, that is 'stick' him, as they say in the jargon of dueling fraternities.'

(90) Message ID <4tsk0s\$n4m@ra.ibr.cs.tu-bs.de>

Schaden können diese Bücher einem nicht zufügen.

'These books can't do any harm to people (lit. add harm to people).'

4.3.2. Iteration. Iteration is a frequent concomitant of concrete uses of the central sense. We saw that predications involving saturation typically involve multiple instances of a given action. For example, predications involving beladen ('be-load') often express scenarios in which many items are loaded in succession. However, the notion of iteration can also be expressed by beverbs independently of the transfer or saturation implications. Example 91 illustrates this:

911) 8805296:

Es kann nicht angehen, daß auch auf kommunaler Ebene Wahlbeamte schon mit vierzig eine Pension beziehen.

'It cannot be the case that even on the municipal level elected officals be-draw a pension already at the age of $40 . '$

This examples illustrates the use of the verb ziehen ('pull, draw') in the applicative pattern to denote regular reception of goods or funds (as when one subscribes to a newspaper or receives 
retirement income). Example 92 presents another case in which an applicative predication prominently expresses iteration:

(92) MMM/912.44101: Mannheimer Morgen, 03.12.1989, Sonstiges

Puppen aus Porzellan mit echtem Lockenkopf und zarten Sommersprösschen gehören für 700 Mark in jede Schicky-Micky-Kinderstube, zumindest eine KätheKruse, trotz des bäuerlichen Gesichtsausdruck ein Prestige-Objekt für höhere Töchter muß her, obgleich vielleicht eine kitschige Barbie im überladenen NylonAbendkleid viel mehr geliebt und bespielt wird.

'For 700 marks porcelain dolls with real curly hair and delicate freckles should be part of every fancy-shmancy playroom; for daughters of the upper-class it has to be at least a Kaethe Kruse - an object of prestige in spite of the rustic physiognomy-although a kitschy Barbie doll in a pretentious nylon evening dress might be loved and played with (lit. be-played) much more.'

In example 92 the be-playing predication does not entail that a given doll might become worn out and ragged as a result of playing. It is also difficult to detect a coverage implication here, since a doll is not a surface which one can cover by means of playing, as in the bespielen predication in 100 below. Instead, what is relevant is the frequency with which the child is likely to play with the Barbie doll. Examples like 92 illustrate the circumstances under which the iteration implication - otherwise a happenstance concomitant of the coverage implication conventionally associated with the applicative pattern - comes to be the sole implication expressed by the bepattern. The iteration implication is the sole feature responsible for contrast pairs like hindern ('stop, prevent') vs. behindern ('hinder').

By assuming an iteration use of the be-pattern, we account for a usage of the verb befahren which otherwise appears to violate a robust constraint on the applicative pattern: the location must be two-dimensional (see section 3.5). Use of befahren to describe car travel appears to violate the planar-location constraint, because the locative argument (the roadway) is a onedimensional rather than two-dimensional location. Examples (93-94) illustrate this usage:

(93) Message ID <7ABkUTL9WpB@ kholdan.snafu.de>

Kennst du die Unfallstatistiken jeder solcher Straßen? Weißt du ganz sicher, wieviele Unfälle dort schon passiert sind?

Wenn ich täglich paarmal eine Straße befahre? Klar. 
'A: Do you know the accident statistics of all such streets? Do you know for sure how many accidents have happened there already? B: If I be-drive that road a few times per day? Of course.'

Message ID <3716ad43.95796920@ news.nacamar.de>

Heute stand mal wieder an einer Straße, die ich oft befahre, ein schöner ZivilPassat mit zwei Leuten drin und einem seltsamen viereckigen Gerät in der Hand ;-) 'Today a nice unmarked Passat happened to park along a road that I be-drive often. In it were two people with a strange rectangular device in their hands.'

The uses in 93-94 are unexpected because they invoke a construal distinct from that associated with the applicative predication involving the sailor and the Baltic Sea in 59 above: in 93-94 there is no two-dimensional location for the driver (and vehicle) to thoroughly cover. The applicative predications in these examples certainly do not lead one to construct a scenario in which a driver is 'covering' the road by swerving her car to the left and right. Nor is there any notion that the driver is driving with particular intensity. Similarly, it is not implied that the road is affected more heavily by be-driving than by some other kind of driving. Rather what is crucial for the uses of befahren in examples 93 and 94 is that driving represents an iterated activity ${ }^{17}$ One may, for instance, be-drive a particular road to work every day. That iteration is crucial to the use of befahren to describe car travel is suggested by the ill-formedness of 95 a as against $95 \mathrm{~b}$ :

(95) a. * Ich befahre heute die A3.
'I'll take/drive on highway A3 today.'
b. Ich fahre heute die A3.
I'll take/drive on highway A3 today.'

The relationship between verb semantics and construction semantics in examples like 91-92 appears to be that of elaboration, since the verb and the construction are each bivalent. In the case of sentence 92, for example, the player and the 'instrument' roles assigned by the verb map to the agent and theme roles assigned by (this sense of) the construction. The elaboration relation is identified when the verb is a more specific instance of the event type designated by the construction. Does this characterization apply to the iteration usage? The applicative construction designates a sequence of iterated events, whereas the verb spielen, e.g., does not denote a sequence of iterated playing events. However, insofar as the verb denotes the event type which is replicated in the constructional semantics, we can identify an elaboration relation in this case. 
4.3.3. Intensification. Numerous be-predications share the notion of intensive action but do not involve coverage of any surface. This intensification sense may be attributed to a pragmatic inference of the following kind. Many be-predications entail repetition of subevents. The repetition of subevents is evidence that the activity is carried out with greater intensity than in the case of comparable isolated events. While we lack diachronic evidence for a path of grammaticalization along these lines, it is plausible in the light of other findings. For instance, Regier (1994), in a typological study of the semantics of reduplication, links the INTENSITYsense of reduplication to the PLURALITY-sense, which in turn is linked to the claimed central sense, REPETITION. An example of a be-predication which exhibits the intensification sense is besiegen 'defeat'. As shown in the following example, besiegen expresses a more decisive resolution of a conflict than does siegen über 'be victorious over':

MK1/WJA.00000, JASPERS, DIE ATOMBOMBE UND DIE ZUKUNFT DES MENSCHEN.

Sollte Rußland den Krieg beginnen - etwa durch Überschreitung der Grenze nach dem Westen, so würde seinen Massenheeren, die mit den konventionellen Waffen Europa schnell besiegen könnten, wahrscheinlich sofort mit Atomwaffen begegnet.

'Should Russia start the war-say by crossing the border to the West-its mass armies, which would be able to defeat Europe quickly with its conventional weapons, would be likely to be responded to with nuclear weapons immediately.'

Similarly, bekämpfen differs from kämpfen 'fight' in implying higher intensity: one is not simply fighting against something, but actively combatting something.

1028294

Die Naturschutzgruppe hält daher Vorschläge bereit, wie man Schädlinge natürlich, ohne Einsatz von chemischen Giften, bekämpfen kann

'The environmentalist group therefore offers suggestions on how you can combat pests naturally, without the use of chemical poisons.'

While the type of action that bekämpfen 'combat' expresses involves repeated engagements, the iteration notion is not by itself enough to warrant the use of this verb: an event involving a 
series of defensive battles could not be described by this verb. Thus, it is the intensification notion that appears to be relevant to the usage of this verb.

Further examples of the intensification function are given in 98-99. The base forms of the applicative verbs shown here are, respectively, schimpfen ('scold') and fürchten ('dread, be afraid of'). Beschimpfen denotes abusive verbal behavior. Befürchten denotes an enhanced state of dread, involving an immediate threat. Example 99 shows that the intensification function of the applicative need not involve any implication of iterated action, since here it is a state predicate which is intensified:

18141081

Es berechtigt sie weder, die Polizei zu beschimpfen und mit Steinen zu bewerfen, noch eine bunte Palette von Wurfgeschossen in Richtung Innenraum zu schleudern.

'It doesn't give them the right to verbally abuse (lit. be-scold) the police and pelt them with stones nor to hurl all manner of projectiles in the direction of the interior.'

\section{5}

Dies lasse für den bevorstehenden Kommunalwahlkampf Schlimmes befürchten.

'This would be reason to fear bad things during the upcoming local elections.'

The relation between the verb and (this usage of ) the applicative construction is again that of elaboration: the verb is a subtype of the situation type denoted by the construction. The situation type denoted by the construction corresponds to an extreme point on a scale for eventualities, whether these are actions (like gaining victories or scolding) or states (like fearing).

4.3.4. Affectedness. One can define affectedness as a change of physical or mental state which is (potentially or actually) effected by some action. A location is potentially affected by the theme's movement across it, as in 100:

(100) MMM/507.07898: Mannheimer Morgen, 14.07.1995, Lokales

Die Frage, ob der Mundenheimer Platz bespielbar ist, wird künftig der Platzwartentscheiden. Eine kleine Einschränkung bleibt: Die Stadt behält sich das Recht vor, anders zu entscheiden, wenn Gefahr besteht, daß das Spielfeld erheblich beeinträchtigt werden könnte. 
'The question whether the Mundenheimer Field can be played on (lit. is beplayable) will in future be decided by the groundsman. But a small restriction remains: the city reserves the right to decide otherwise if there is a danger that the field could be damaged considerably.'

AFFECTEDNESS is a frequent concomitant of SATURATION: damage to the soccer field results from the players' sequential or summary coverage of the field. As we pointed out earlier, however, saturation does not entail affectedness. For instance, in the static bewohnen 'be-live' scenario denoted by sentence 61 , repeated here as 101, the inhabitants of the town center of Altriper do not necessarily affect their surroundings through their habitation:

(101) MMM/102.37001: Mannheimer Morgen, 09.02.1991, Leserbriefe;

Die alteingesessenen Altriper, die den Ortskern bis jetzt noch bewohnen, werden sich eben mit dem noch stärker werdenden Durchgangsverkehr abfinden müssen.

'The long-time Altriperians who up until now are still living in (lit. be-living) the town center will just have to get used to the increasing through traffic.'

There is here no implication that the inhabitants wear out their homes or the streets in their neighborhood. (The notion of abuse through habitation is in fact lexicalized, separately by the verb abwohnen, lit. 'live down'.) Thus coverage does not entail a change of state in the location, although affectedness is a frequent implication of predications involving coverage. We contend that this implication is the basis for an extended usage of the applicative pattern in which only affecting and not coverage is entailed. Predications which exemplify this usage express the means by which the effect is achieved. For example, most speech-act verbs can be used in the applicative pattern to denote a means of annoying the recipient:

(102) Süddeutsche Zeitung, November 28, 1992

HEADLINE: Die Leute wollen sich nicht belabern lassen. n-tv-Geschäftsführer. Karl-Ulrich Kuhlo über die Chancen seines Nachrichtenprogramms, das am Montag auf Sendung geht.

'HEADLINE: People don't want to be blathered at (lit. be-blathered). N-tv executive Karl-Ulrich Kuhlo about the prospects for his news channel, which goes on the air Monday.'

These uses of speech-act verbs do not appear to be based upon a metaphorical mapping whose source domain involves saturation or coverage, e.g., the SPEECH IS TRAVEL ACROSS A TOPIC 
metaphor. Instead, speech-act verbs in examples like 102 express the means by which an effect is achieved. While in 102 this effect is unintended, the effect may also be an intended one, as in 103:

(103) Message ID <3779D77E.EC802A73@fh-konstanz.de>

Meistens muß man den selber einbauen. Außer du bist sehr gut im Leute bequatschen.

'In most cases you have to install it yourself. Except if you're very good at persuading (lit. be-talking) people.'

Applicative verbs of domestic and culinary activity also frequently express the means by which a (beneficial) effect is achieved. Sentence 104 (a response to an on-line personals ad) exemplifies this usage of the applicative for the verbs kochen ('cook') and putzen ('clean'):

$<35666380.12664736 @$ news.netway.at>

Und wenn Du [...] arbeitest, mir das Geld ins Haus trögst, mach' ich die Kinder (gebären mußtest Du sie bitte), mach' ich den Haushalt, bekoch' dich (und hoffe Dir schmeckt's), beputz' Dich (waschen mußt' Dich selber), und halt' Dir die Kinder vom Leib.

'And if you work [...] and bring the money home, then I'll take care of the kids (you just have to give birth), I'll take care of the house, I'll be-cook you (hope you like what I cook), be-clean you (you have to wash yourself yourself), and keep the kids out of your way.'

Crucially, the role of the object-denotatum is that of beneficiary rather than theme. The theme argument licensed by the verb can be expressed by an oblique, as in the example of bekochen in 1, ([...] habe ich mich [...] mit Kaffee bekochen lassen 'I had myself be-cooked with coffee'). However, this oblique could be analyzed as an instrumental adjunct, as it clearly is in 105:

<36969A47.ADA335C0@gmx.net>

Ich habe sogar vor, meine Wohnebene (Uni) am Wochenende als Versuskaninchen zu benutzen. Ich habe schon Tage lang nach einem guten Rezept gesucht, mit dem ich meine Mitstudenten am Wochenenede bekochen kann.

'I am even planning on using the people on my floor (college dormitory) as guinea pigs. I have been looking for days now for a good recipe with which I can be-cook my fellow students over the weekend.' 
The theme is not construable as an instrument in the case of beputzen, and an oblique theme is accordingly ruled out, as shown in 106:

(106) *Die Haushälterin beputze mich mit der Küche

'The housekeeper be-cleaned me with the kitchen'.

It is not obvious, however, why an oblique theme should require an instrumental construal, since it does not necessarily receive one. Because the oblique theme is licensed by the Oblique Theme construction, the grammaticality contrast at issue here appears to hinge on the applicability of that construction. As represented in section 3.8, the Oblique Theme construction denotes a transfer event. However, we have said that the version of the applicative pattern which carries the affectedness implication is bivalent, and owes nothing directly to the semantics of transfer. How then do we describe the anomalous nature of 106? Since we allow linking constructions to augment verbal valence, with concomitant semantic effects, there seems to be no reason to prevent the Oblique Goal construction from combining with the bivalent applicative pattern which denotes affecting. This combination would have the effect of adding a theme argument and imposing a construal in which the benefactive activity entails transfer. Insofar as culinary activity entails transfer to the beneficiary, this construal is coherent. Since benefaction via cleaning does not entail transfer, unification of beputzen with the Oblique-Theme construction does not yield a coherent construal. ${ }^{18}$

The affectedness implication associated with applicative sentences like 104-105 is typically associated either with an iteration implication, as when habitual beneficial activity is denoted (104), or a coverage implication, as when a bounded set of individuals is serviced (105). The affectedness, coverage and iteration implications may be present simultaneously, as in 107:

(107) http://www.tagesspiegel.de/ressorts/portrait/B/BONA400.HTM

Täglich holen einige Obdachlose aus der Teestube frische Brötchen und Kuchen in der Bäckerei ab. 60-80 Menschen zu bebacken, kostet Bonau und seine Mitarbeiter am Tag eine gute Viertelstunde Arbeit. Das ist—laut Bonau—nicht der Rede wert.

'Every day some homeless people from the tea room pick up fresh rolls and cake in the bakery. To be-bake 60-80 people takes Bonau and his employees fifteen minutes of work per day. That's hardly worth mentioning, says Bonau.' 
In 107, a coverage interpretation is possible because the group of beneficiaries, via its cardinality, 'measures out' the baking event — this event is completed when all of the individuals in the group are provided for. Since the event (as described) is iterated daily, the iteration implication is present here as well. The mutual compatibility of the (otherwise separable) coverage, affectedness and iteration implications in the interpretation of 107 is unsurprising on the present account, since each of these notions belongs to a single coherent event schema. However, nonce formations like 108 show that there are productive uses of the applicative pattern which exploit the affectedness implication alone:

(108) Süddeutsche Zeitung, May 27, 1995

[..] und während einem die heißen Rhythmen der kubanischen Musik in die Glieder fahren, strömen lächelnde Mädchen, zweifelsfrei Sendboten eines fernen Planeten der Freude, in die graue Welt, von vorne, von hinten, von den Seiten, angetan mit Flitter und Tand, mit Federbüschen und Riesenblumen, mit Durchsichtigem und Undurchsichtigem, und sie betanzen dich, behexen dich, verwirren dich, machen dir warm ums Herz, und das 30-Mann-Orchester spielt wie entfesselt, und in den bunten Nebeln baden in natürlicher Eleganz die Königinnen der Illusion.

'.... and while the hot rhythms of Cuban music get to you, smiling girls-undoubtedly messengers of a far away planet of joy-stream into the gray world from all sides, clad in tinsel and finery, plumes and giant flowers, in transparent and nontransparent clothes, and they be-dance you, bewitch you, confuse you, make you feel hot, and the 30-member orchestra plays as if in a rage, and the queens of illusion bask with natural elegance in the multi-colored mists.'

In the use of betanzen 'be-dance' in 108 the beneficiary receives the accusative coding otherwise associated with the location argument, and therefore there is no notion of coverage of the stage, etc. The only semantic factor that links this use of $b e$ - to other senses is the implication of affectedness: the dancers affect the audience by means of their performance.

4.3.5. Act in a particular capacity toward someone. This small group of denominal beverbs includes bemuttern ( $<$ Mutter 'mother'), bewirten ( $<$ Wirt 'host'), bespitzeln ( $<$ Spitzel 'spy'). Examples are given in 109 and 110:

Message ID <slrn6sf8ab.61.bones@castle.aball.de> 
Männer möchten auch zuweilen dominiert (bemuttert) werden, dann brauchen sie nämlich auch nur zu empfangen und sind jeglicher Verantwortung (und Konsequenzen) enthoben.

'At times, men want to be dominated (be-mothered), too. For then they only have to receive and they are relieved of any responsibility (and consequences).'

(110) http://www.phil.uni-passau.de/dlwg/ws07/12-1-97.txt

Mesmer hatte die Heilung der (durch eine Lähmung des Sehnervs) erblindeten Klavierspielerin Paradis erzielt; der Fall machte um so mehr Aufsehen, als die junge, offenbar übernervöse Musikerin von der Kaiserin Maria Theresia begönnert wurde.

'Mesmer had succeeded in healing the pianist Paradis who had gone blind (due to paralysis of her optic nerve); the case drew all the more attention since the young, apparently hyper-nervous musician was patronized (lit. be-patroned) by the empress Maria Theresia.'

These verbs differ from other denominal be-verbs in an important respect: the source nominal does not express the type of the theme argument, as it does in the case of applicative verbs with literal transfer semantics, e.g., beschildern ('be-sign') in 52 or in the case of applicative verbs which evoke the effects-as-transferred-objects metaphor, e.g., befrieden ('be-peace') in 53. Instead, the nominal base in examples 109-110 expresses the type of role assumed by the AGENT of the event. The agent's assumption of this role is a precondition upon the agent's achieving a particular effect upon the beneficiary. Therefore, we view this usage as inductively related to the affectedness usage discussed in 4.3.4: an agent may affect a beneficiary by assuming a particular role relative to that individual. This fairly weak inductive relationship is expressed by a semanticextension link labeled means in Figure 4. This use of the term means is distinct from that in which the term refers to a particular verb-construction integration relation. The verb-construction integration relation which we assume for bemuttern and other applicatives of this class is the instance (or, equivalently, elaboration) relation. As in the case of denominals like beschildern, we postulate a type-shifting effect in which the base nominal receives a valence set via unification with the applicative construction. The arguments in the valence set of the applicative construction fuse with the corresponding participant roles in the frame semantics of the particular noun. In the case of bemuttern, for example, these participant roles are the mother and the child. These frame-specific roles fuse with the corresponding roles licensed by the (bivalent) applicative construction. In accordance with our general treatment of denominal applicatives, we 
reject the view that the base noun, e.g., Mutter, 'denotes' a particular participant in the event expressed by the predication, in this case an agent. Instead, the source nominal denotes a type, permitting omission of the agent argument where type information is sufficient, as in 109.

4.4. Historical evidence. The most plausible source for the semantics of coverage associated with the be-pattern is the 'around' schema associated with the historic precursor of be, the preposition bi. The modern English and German prepositions meaning 'around'-around and um/herum respectively_are ambiguous between a sense of 'surrounding an enclosed space' and 'being distributed over a surface area'. Consider the following data:

(111) Die Spieler versammelten sich um den Trainer.

'The players gathered around the coach.'

(112) Die Spieler standen auf dem Platz herum und warteten auf den Schlußpfiff.

'The players were standing around the pitch waiting for the final whistle.' (lit. '... around on the pitch...')

(113) Die Abwehrspieler liefen orientierungslos auf dem Platz herum.

'The defense were running around the pitch disoriented.' (lit. '... around on the pitch...')

In 111 we see that um/herum can denote a static surrounding configuration. In 112 we see that um/herum can denote a static configuration involving coverage of a surface by multiple points. In 113 we see that the coverage scene expressed by um/herum like that expressed by English around, is consistent with a dynamic scene in which a surface over the course of time. The prefix be- had the set of senses that um/herum and around display in 111-113 through Grimm's time. Grimm lists Latin circum as the first sense for the be-prefix. But, as Ruppenhofer (1999) showed, $b e$-verbs exemplifying the surrounding usage seen in 111 were already being lost in Grimm's time and continued to be lost thereafter. Among these lost verbs were, for instance, bearmen 'embrace'; bezäunen 'fence in'; and behüllen 'surround'. Only, a small number of beverbs which denote surrounding or containment remain. Among these verbs is beherbergen 'shelter, harbor', which has both bivalent and trivalent uses. Bivalent beherbergen is exemplified in 114: 
4037381

Das Schloßmuseum wurde 1908 eingerichtet und beherbergt außer prächtigen Stilmöbeln, englischen Gartenhockern und Leuchtern besonders kostbare Tafel- , Tee- und Kaffeeservices, geschmackvolles Geschirr und Porzellan-Zierat .

'The castle museum was established in 1908 and harbors (lit. be-shelters) particularly precious dinner, tea, and coffee services, tasteful dishes and porcelain ornaments in addition to magnificent period furniture, English garden seats, and chandeliers.'

Example 115 illustrates trivalent beherbergen:

(115) 9921167

Nach den Worten von Riebel beherbergt der Kreis bereits 1500 Asylbewerber in 55 Unterkünften.

'According to Riebel, the county is already providing accommodation to (lit. be-sheltering) 1500 asylum seekers in 55 shelters.'

Another clear example of the surrounding sense is begrenzen 'mark off, form the boundary of':

1093227

Als zukünftigen Standort schlägt die Friedberger CDU ein dem Wetteraukreis gehörendes Gelände vor, das westlich der Stadthalle liegt und begrenzt wird von der Ockstädter und Johann-Peter-Schäfer-Straße, dem Seebach und dem Parkplatz der Stadthalle.

'The Friedberg CDU [political party] proposes as future location an area belonging to Wetterau county that is delimited (lit. be-bordered) by Ockstädter Street and Johann-Peter-Schäfer Street, the Seebach [a brook], and the parking lot of the municipal hall.'

The surrounding sense of the prefix is no longer productive. ${ }^{19}$ The surrounding class might be regarded as a low-productivity verb cluster associated with the applicative pattern. However, we chose to omit the surrounding class from our semantic analysis of the applicative pattern because the $b e$-verbs which continue the semantics of enclosure do not share the linking constraints which we have identified with the applicative pattern. For example, the subject of bivalent (active voice) beherbergen is a location rather than a theme (as in 114), and the object of trivalent (active voice) beherbergen is a theme rather than a location. While the surrounding sense of the be-prefix 
survives in a small set of verbs, the related sense of the prefix involving coverage of a surface is part of the highly productive applicative construction. ${ }^{20}$

By delineating the various entailments of the enclosure sense, we can understand not only the development of the coverage sense of $b e$ - but also the development of a PROXIMITY meaning which continues in the non-bound preposition bei and, like the surrounding sense, is preserved in a few be-verbs. Following Grimm (1854: 1203), we treat the proximity meaning as having arisen by metonymy from the 'surrounding'-sense: what is in the vicinity of an object is close to it. An explanation along these lines is plausible since, for instance, the English preposition around has uses with the same implication of proximity, e.g. John likes to be around his family. The same is true for the Modern German preposition um, which also can be used in sentences like Er hat seine Familie gerne um sich ('He likes to have his family around him'), where closeness to the theme or location rather than surrounding or enclosure of the theme is involved. Be-verbs which might be viewed as preserving the proximity semantics of the prefix are bekommen ('get, obtain'), belangen ('sue, prosecute'), besteigen ('mount, climb, climb into'), and betreten ('enter'), all of which are attested with such meanings in Middle High German (Lexer 1872). Literal glosses, which express the semantic contribution of the prefix, are, respectively: 'come upon' (as in the English verb come by, meaning 'to obtain'), 'reach toward', 'ascend to', and 'step onto'. Another class of verbs which appears to preserve the proximity-denoting sense of the prefix are statives which denote scenes in which a theme remains in place. Included within this class are: behalten, 'keep' (lit. 'hold near'); belassen, 'leave in place' (lit. 'leave by a place'); beruhen, 'be based on' (lit. 'rest on'); and bestehen, 'exist, insist' (lit. 'stand by a place').

By treating the proximity, enclosure and coverage readings as components of a single semantic schema, we can account for a layering effect observable within the class of be-verbs: while the majority of $b e$-verbs (and the totality of coinages in our corpus data) express notions related to the coverage component, certain small classes continue meanings associated with other components of that schema. As shown by the examples involving English and German um/herum, the patterns of semantic extension proposed both here and by Grimm for the beprefix are plausible. These patterns collectively define a continuum of idiomaticity in the modern language: some instances of the applicative pattern represent transparent combinations of constructional and verbal semantics whereas others cannot be related to the semantic schema which defines the productivity of the construction.

Our proposal that the 'coverage' sense of the applicative pattern is the prototypical usage receives support not only from the fact that this class has the highest type frequency in our corpus (see Ruppenhofer \& Michaelis in press, Appendix), but also from observations about the patterns of loss and innovation within the class of $b e$-verbs over the last 200 years. For instance, a once sizeable class of verbs with removal semantics has lost all of its members, with the 
exception of the idiomatic verbs of theft discussed earlier. No new removal verbs have been innovated outside of the small theft subclass. By contrast, be-verbs with concrete coverage meanings have been innovated in great number. Examples include bespiken, put spikes onto [e.g., tires of motocross bikes]'; bestrahlen 'illuminate; irradiate [e.g., food]'; beampeln 'put up traffic lights [e.g., at intersections]'. Although the coverage class has lost members as well, these losses are piecemeal and appear to be due to lexical obsolescence (e.g., beleitern 'put ladders down mining shafts [for access]'; bezetteln 'put little pieces of paper on [as labels]'; belehnen 'invest with a fiefdom'; befrohnen 'impose corvée on').

\section{Conclusion}

We have sought to establish that the German applicative pattern should be described as a symbolic unit rather than as the product of a lexical rule. By examining constraints and effects which are directly attributable to the be-pattern (valence creation and augmentation, holistic and planar interpretation of the location argument), we have suggested that this argument-structure pattern does something that only verbs are generally thought to do: denote an event type. Since a syntactic construction can mean what it means in the way that a word means what it means-via convention-it makes sense that an argument-structure pattern should, like a polysemous word, denote an associative network of senses; we have discussed the prototype-based semantics of coverage associated with the be-pattern.

Along with Bybee et al. (1994), we adopt the view that the semantic substance associated with a given formative is the accretion of a series of diachronic developments. Like these authors, we see the diachronic dimension as greatly increasing the explanatory power of semantic theory. As they point out, one cannot explain the existence of a particular construction by showing that it has a particular function or functions; one must also explain how that construction developed its functions (p. 3). Describing the relevant patterns of semantic extension is a coherent enterprise only if one assumes a sign-based semantics for constructions. In accordance with Goldberg (1995), we maintain that to admit 'top down' or syntactic meaning does not conflict with the goal of providing a compositional theory of sentence semantics: on the constructional account, sentence interpretation is a procedure by which the situation type denoted by a predicate-argument complex is related to the situation type denoted by the construction. 


\section{References}

Alsina, Alex and SAm MCHOMBo. 1990. The Syntax of Applicatives in Chichewa: Problems for a Theta Theoretic Asymmetry. Natural Language and Linguistic Theory 8: 493-506.

Bennet, Michael and BARbARA PARTEE. 1978. Toward the Logic of Tense and Aspect in English. Indianapolis: Indiana University Linguistics Club.

BiCKEL, BAlThASAR. 1997. Aspectual Scope and the Difference between Logical and Semantic Representation. Lingua 102: 115-131.

BIERWISCH, MANFRED. 1988. On the Grammar of Local Prepositions. In M. Bierwisch et al., (eds.), Syntax, Semantik und Lexikon. Berlin: Akademie-Verlag.

BRESNAN, JOAN. 1994. Locative Inversion and the Architecture of Universal Grammar. Language 70. 72-131.

BRINKMANN, URSULA. 1997. The Locative alternation in German: Its Structure and Acquisition. Amsterdam: John Benjamins.

BYBEE, JOAN. 1985. Morphology: A Study in the Relationship between Meaning and Form. Philadelphia: Benjamins.

1995. Regular Morphology and the Lexicon. Language and Cognitive Processes 10 : 425-455.

, R. Perkins and William Pagliuca. 1994. The Evolution of Grammar. Chicago: University of Chicago Press.

Clark, Eve and Herbert Clark. 1979. When Nouns Surface as Verbs. Language 55.767-811.

COMrIE, Bernard. 1976. Aspect. Cambridge: Cambridge University Press.

DowTY, DAVID. 1991. Thematic Proto-roles and Argument Selection. Language 67.547-619.

EROMS, HANS-Werner. 1980. Be-Verb und Präpositionalphrase. Heidelberg: Carl Winter Universitätsverlag. 
FAUCONNIER, GILLES. 1985. Mental Spaces. Chicago: University of Chicago Press.

FAUCONNIER, GILleS and MARK TURNER. 1996. Blending as a Central Process of Grammar. Conceptual Structure, Discourse and Language, ed. by Adele Goldberg, 113-130. Stanford: CSLI Publications.

Fillmore, ChARLES J. 1968. The Case for Case. Universals in Linguistic Theory, ed. by E. Bach and R. Harms. New York: Holt, Rinehart \& Winston.

. 1977. The Case for Case Reopened. Syntax and semantics, Vol. 8: Grammatical relations, ed. by P. Cole \& J.M. Saddock. New York: Academic Press.

. 1982. Frame Semantics. Linguistics in the Morning Calm, ed. by Linguistic Society of Korea, 111-38. Seoul: Hanshin.

. 1985. Frames and the Semantics of Understanding. Quaderni di Semantica 6:2.222-53.

. 1986. Pragmatically Controlled Zero Anaphora. Berkeley Linguistics Society 12.95107.

Fillmore, Charles J. and Paul Kay. 1997. Construction Grammar. Berkeley: University of California, ms.

FILIP, HANA. 1994. Aspect and the Semantics of Noun Phrases. Tense and Aspect in Discourse, ed. by Carl Vetters, 227-255. Berlin: Mouton de Gruyter.

FOLEY, WiLliam and Robert VAN VALIN. 1984. Functional syntax and universal grammar. Cambridge: Cambridge University Press.

GÖBEL, UlRICH and OSKAR REICHMANN (eds.). 1999. Frühneuhochdeutsches Wörterbuch. Berlin: Walter de Gruyter.

GOLDBERG, ADELE. 1995. Constructions: A Construction Grammar Approach to Argument Structure. Chicago: University of Chicago Press. 
1997. The Relationships between Verbs and Constructions. In Lexical and Syntactical Constructions and the Construction of Meaning, ed. by R. Dirven and E. Sweetser. 383-398. Amsterdam: Benjamins.

GRIMM, JACOB and WiLHELM GRIMM. (eds.) 1854. Deutsches Wörterbuch. Leipzig: Verlag von S. Hirzel.

Gropen, J.; S. Pinker; M. Hollander; R. GoldberG; and R. Wilson. 1989. The Learnability and Acquisition of the Dative Alternation in English. Language 65.203-257.

—-,,$- \ldots+$ - 1991. Affectedness and Direct Objects: The Role of Lexical Semantics in the Acquisition of Argument Structure. Cognition 41.153-195.

Hale, Kenneth and SAmuel J. Keyser. 1993. On Argument Structure and the Lexical Expression of Syntactic Relations. The View from Building 20: Essays in Honor of Sylvain Bromberger, ed. by Kenneth Hale and Samuel J. Keyser. 53-109. Cambridge: MA: MIT Press.

Herweg, Michael. 1991. A Critical Account of two Classical Approaches to Aspect. Journal of Semantics 8: 362-403.

Hinkelman, Elizabeth A. and James F. Allen. 1989. Two Constraints on Speech Act Ambiguity. Proceedings of the Twenty-seventh Annual Meeting of the Association for Computational Linguistics.

HOPPER, PAUl J. 1985. Causes and Affects. Chicago Linguistic Society 21:2.67-88.

and Sandra A. Thompson. 1980. Transitivity in Grammar and Discourse Language 56: 251-99.

--, and Elizabeth C. Traugott. 1993. Grammaticalization. Cambridge: Cambridge University Press.

HoRn, LAWRENCE. 1984. Toward a New Taxonomy for Pragmatic Inference: Q-based and Rbased Implicature. Georgetown University Round Table on Languages and Linguistics: 
Meaning, form, and use in context, ed. by D. Schiffrin, 11-42. Washington: Georgetown University Press.

1989. A Natural History of Negation. Chicago: University of Chicago Press.

JACKENDOFF, RAY. 1983. Semantics and Cognition. Cambridge, MA: MIT Press. 1990. Semantic Structures. Cambridge, MA: MIT Press. 1997a. The Architecture of the Language Faculty. Cambridge, MA: MIT Press. 1997b. Twistin' the Night Away. Language 73: 534-570.

KAy, PAul and Charles J. FILlmore. 1999. Grammatical Constructions and Linguistic Generalizations: The What's X Doing Y? Construction. Language 75: 1-33.

KoEnIG, JEAN-PIERRE. 1993. Linking Constructions vs. Linking Rules: Evidence from French. Berkeley Linguistics Society 19. 217-231.

KONIG, EKKEHARD and EliZABETH TRAUGOTT. 1982. Divergence and Apparent Convergence in the Development of Yet and Still. Berkeley Linguistics Society 8. 170-179.

- 1988. Pragmatic Strengthening and Semantic Change: The Conventionalizing of Conversational Implicature. In Werner Hullen and Rainer Schulze, (eds.), Understanding the Lexicon: Meaning, Sense and World Knowledge in Lexical Semantics. Tubingen: Niemeyer. 110-124

LAKOFF, GEORGE. 1987. Women, Fire, and Dangerous Things: What Categories Reveal about the Human Mind. Chicago: University of Chicago Press.

. 1990. The Invariance Hypothesis: Is Abstract Reason Based on Image-Schemas? Cognitive Linguistics 1. 39-74

--, and MARK JOHNSON. 1980. Metaphors we Live by. Chicago: University of Chicago Press. 
LANGACKER, RONALD W. 1987. Foundations of Cognitive Grammar, vol. 1: Theoretical Prerequisites. Stanford: Stanford University Press.

LEBEAUX, DAVID. 1988. The Feature [+affected] and the Formation of the Passive. Syntax and Semantics, vol. 21: Thematic Relations, ed. by W. Wilkins. New York: Academic Press.

LEVIN, BETH. 1993. English Verb Classes and Alternations: A Preliminary investigation. Chicago: University of Chicago Press.

LeXER, MATTHiAs (ed.). 1872. Mittelhochdeutsches Handwörterbuch. Leipzig: Verlag von S. Hirzel.

LÖBNER, SEBASTIAN. 1990. Wahr neben falsch: Duale Operatoren als die Quantoren natürlicher Sprache. Tübingen, Germany: Niemeyer.

LOSIEWICZ, BETH. 1992. The Effect of Frequency on Linguistic Morphology. Doctoral thesis, University of Texas at Austin.

Marcus, Gary F.; Ursula Brinkmann; Harald Clahsen; Richard Wiese; and Steven PINKER. 1995. German Inflection: The Exception that Proves the Rule. Cognitive Psychology 29. 189-256.

Michaelis, LaurA A. 1993. On Deviant Case-marking in Latin. Advances in Role and Reference Grammar, ed. by Robert D. Van Valin, Jr. Amsterdam: Benjamins.

. 1994. A Case of Constructional Polysemy in Latin. Studies in Language 18.45-70.

and KNUD LAMBRECHT. 1996. Toward a Construction-Based Model of Language Use: The Case of Nominal Extraposition. Language 72.215-247.

and JOSEF RUPPENHOFER. forthcoming. Beyond Alternations: A Constructional View of the German Applicative Pattern. Stanford: CSLI Publications. 
Morgan, Jerry. 1978. Two Types of Convention in Indirect Speech Acts. Syntax and Semantics, vol. 9: Pragmatics, ed. by Peter Cole. New York: Academic Press.

PinKeR, StEVEn. 1989. Learnability and Cognition: The Acquisition of Argument Structure. Cambridge, MA: MIT Press.

PinKeR, SteVEn and ALAN PRINCE. 1991. Regular and Irregular Morphology and the Psychological Status of Rules of Grammar. Berkeley Linguistics Society 17.230-251.

Pustejovksy, James. 1995. The Generative Lexicon. Cambridge, MA: MIT Press.

RAPPAPORT, MALKA and Beth LeVIN. 1988. What to do with Theta Roles. Syntax and Semantics, vol. 21: Thematic relations, ed. by W. Wilkins. New York: Academic Press.

Rappaport Hovav, Malka and Beth Levin. 1998. Building Verb Meanings. The Projection of Arguments, ed. By M. Butt and W. Geuder. Stanford: CSLI Publications.

Reddy Michael. 1979. The Conduit Metaphor. Metaphor and Thought, ed. by A. Ortony. Cambridge: Cambridge University Press.

REGIER, TERRY. 1994. A Preliminary Study of the Semantics of Reduplication. Technical Report TR-94-019, International Computer Science Institute, Berkeley, CA.

RUPPENHOFER, JOSEF. 1999. Lexical change across a Semantic class. Paper presented at the annual meeting of the Linguistic Society of America, Los Angeles.

SLOBIN, DAN. 1997. There's More than One Way to Talk about Motion: Consequences of Linguistic Typology for Narrative Style. Paper presented at the Third Conference on Conceptual Structure, Discourse and Language, University of Colorado at Boulder.

SweEtser, Eve. 1987. Metaphorical Models of Thought and Speech: A Comparison of Historical Directions and Metaphorical Mappings in the two Domains. Berkeley Linguistics Society 13.446-459.

. 1990. From Etymology to Pragmatics. Cambridge: Cambridge University Press. 
TALMY, LeONARD. 1985. Lexicalization Patterns: Semantic Structure in Lexical Forms. Language Typology and Syntactic Description, vol. 3: Grammatical categories and the lexicon, ed. by T. Shopen, 57-149. Cambridge: Cambridge University Press.

TALMY, LeONARD. 1988. The Relation of Grammar to Cognition. Topics in Cognitive Linguistics, ed. by B. Rudzka-Östyn, 165-205. Amsterdam: Benjamins.

Tenny, CAROL. 1987. Grammaticalizing Aspect and Affectedness. Cambridge, MA: MIT dissertation.

VAN VALin, Robert D. and RANDY J. LAPolla. 1997. Syntax: Structure, Meaning and Function. Cambridge: Cambridge University Press.

WUNDERLICH, DIETER. 1987. An Investigation of Lexical Composition: The Case of German beverbs. Linguistics 25.283-331.

Wunderlich, Dieter. 1991. How do Prepositional Phrases Fit into Compositional Syntax and Semantics? Linguistics 29.591-621.

WUNDERLiCH, DiETER. 1994. Towards a lexicon-based theory of agreement. Theoretical Linguistics 20.1-35.

WUNDERLICH, DIETER. 1997. Cause and the Structure of Verbs. Linguistic Inquiry 28.27-68.

ZWICKY, ARNOLD. 1989. What's become of Derivations? Defaults and Invocation. Berkeley Linguistics Society 15.

ZWICKY, ARNOLD. 1994. Dealing out Meaning: Fundamentals of Syntactic Constructions. Berkeley Linguistics Society 20. 


\section{Endnotes}

${ }^{1}$ We gratefully acknowledge the many helpful comments and suggestions provided by two anonymous reviewers. Of various colleagues who have been helpful in the development of the present work, we would like to thank in particular Adele Goldberg, Paul Kay, Knud Lambrecht, George Lakoff, Dan Jurafsky and Andreas Kathol. We also owe a great debt of gratitude to Michael Knölker for his insightful and tireless help with the German data. This paper is dedicated with appreciation and affection to Ekkehard König, on the occasion of his sixtieth birthday.

${ }^{2}$ Our data come from six different sources and are identifiable in the following ways. Examples taken from the on-line corpora at the Institut für Deutsche Sprache begin with a sequence of capital letters and numbers coding the specific corpus they are taken from (e.g. $W K=$ Wendekorpus). Examples taken from the Deja news service on the worldwide web start out with the words Message Id. Data from the Lexis-Nexis research service start out with the name of the journal, newspaper, or magazine the quote is taken from (e.g. Süddeutsche Zeitung). Examples taken from the Frankfurter Rundschau Korpus are marked by a single number. Examples collected from websites are given in the standard URL format. Examples which were provided by native-speaker consultants carry no marking.

${ }^{3}$ This is the Wunderlich 1987 account. It is not entirely clear from the paper, but Wunderlich 1997 may further decompose verbs like PUT into CAUSE (BECOME (LOCATED)).

${ }^{4}$ 'Modifier' is Wunderlich's term for an optional verbal argument.

${ }^{5}$ Brinkmann (1997) uses the term indivisibility to refer to what Löbner calls holism. We adopt the newer terminology.

${ }^{6}$ We will ignore here the problem of enriched composition discussed above.

7 'Ein Prädikat P mit einem Anwendungsbereich, in dem eine Teil-von-Relation definiert ist, ist genau dann summativ, wenn für alle i aus seiner Domäne und für alle zulässigen Aufteilungen $\mathrm{A}$ von i gilt:

$\mathrm{P}(\mathrm{i})=1 \mathrm{gdw}$. [genau dann, wenn; JR\&LAM] P(i') = 1 für alle i' aus A' (p. 25).

8 'Integrative Prädikationen übertragen sich nicht von dem Argument auf beliebige Teile davon, in vielen Fällen sogar auf überhaupt keine echten Teile' (p. 25).

${ }^{9}$ Not all trivalent applicative predications are telic, as we will demonstrate in section 4.1.

${ }^{10}$ This more recent compositional principle is framed within a model which allows for an enriched conception of composition. In the enriched conception, the principle of syntactically transparent composition is treated as a default. The extended conception of composition allows for cases in which material that is not expressed by lexical items of the sentence may nevertheless be part of the conceptual content of the sentence. These are cases of coercion, in which extra meaning is 'added' in order to achieve well-formedness in conceptual structure and/or to 'satisfy 
the pragmatics of the discourse or extralinguistic context' (p. 49). For example, the 'iteration' feature is added to a sentence like I blinked for two minutes because a single blink cannot plausibly be viewed as lasting two minutes. The problem with Jackendoff's analysis, as we see it, is that coercion does not seem to have anything to do with the meaning of the syntactic pattern employed; Jackendoff does not posit a locus of association between semantic properties and syntactic form, i.e., a construction. For this reason, it would seem that coercion phenomena described by Goldberg (1995) and discussed in this section could not be easily handled by Jackendoff's coercion principle - the verb meaning is not modulated by particular co-occurring words or phrases, but by the particular linking configuration with which the verb integrates.

${ }^{11}$ For fusion to take place, the relevant roles of verb and construction need not always be identical; they may instead by merely compatible, as in the case of befahren ('be-drive'), illustrated in 68. The bivalent version of the be-construction calls for a theme, while the verb fahren supplies an agent. However, since this verb denotes directed motion, the agent is also a theme, and therefore fusion of the verb's agent argument and the construction's theme argument is straightforward — the subject denotatum can easily be construed as both agent and theme.

${ }^{12}$ A more extensive representation of the constructions in Figures 1 and 2 would show the unification requirement between elements in the event structure denoted by the construction and elements in the valence set of the construction. We have avoided showing unification indices in order to simplify the diagrams to the extent possible.

${ }^{13}$ A reviewer has questioned the necessity of positing two Applicative constructions, suggesting that the two may be combined into a single construction. While considerations of parsimony would support should a move, we see compelling reasons to distinguish two versions of the Applicative construction. First, the two constructions require distinct aspectual characterizations, as described in 3.8. Second, since the situation type denoted by a linking construction must be of determinate valency, we would have to propose either a bivalent or trivalent Applicative. This fixing of valency would give us an undesired result. If, on the one hand, the proposed Applicative construction were trivalent, there would be no construction to license bivalent applicative predications, and we would incorrectly predict the existence of trivalent applicatives formed from bivalent verbs like wandern, 'wander' (see fn. 14). If, on the other hand, the proposed Applicative construction were bivalent, it would not unify with trivalent verbs like laden ('load'), since the agent argument would fail to receive syntactic expression.

${ }^{14}$ How do we ensure that each verb unifies with the appropriate version of the applicative construction? As it stands, there is nothing to prevent a trivalent verb like laden 'load' from unifying with the bivalent version of the applicative construction. Although the agent of laden would not fuse with any role in the theta frame of the applicative construction, it would be linked to the SUBJECT grammatical function by default Subject Principle, since the theme and location are each subject to more specific linkings-Oblique Theme and Applicative, respectively. We also have no obvious way to prevent a bivalent verb like wandern 'wander' from unifying with the causative (trivalent) version of the Applicative construction. In such an instance, the Applicative would merely contribute an agent to the verb's valence and require nonoblique expression of the location. The theme would be subject to the Oblique Theme linking, and the 
agent would again receive subject coding by the default Subject Principle. By allowing such unification, we overgenerate, since bewandern, e.g., could not be used to denote causation of coverage. It appears that we must stipulate an optimization principle whereby the verb unifies with that version of the Applicative whose valency is closest to its own.

${ }^{15}$ Within the class of $b e$-verbs denoting thorough discussion, there are, however, relatively recent additions. For example, besprechen 'discuss' seems to have lacked the 'discuss' sense in Middle High German but meant only '1. agree on 2. talk to, address 3. accuse of 4. consult, confer [used with reciprocal sich]'.

16 The analysis presented here does not extend to what we may call pseudo be-participles, i.e., to forms that look like participles of $b e$-verbs but do in fact not have any related inflected forms. For instance, for beamtet 'being state appointed [e.g. as a teacher, judge, etc.]' there is no corresponding verb *beamten. These ornative applicative participles are analogous to uses of the English past participle to convey attributes, e.g., long-haired. See Langacker 1991 for a discussion of the semantic relationship between this use of the past participle and others.

${ }^{17}$ There is, however, an idiomatic use of befahren which lacks the iteration implication. It is a piece of officialese used primarily in reports on traffic accidents and easily identifiable by the fact that in the overwhelming majority of cases the direction in which the driver was driving on the road is given. An example of this idiomatic usage is the following:

4321018

Einem Bad Nauheimer Autofahrer, der am Freitag gegen 14.40 Uhr die Wetteraustraße in Dorheim in Richtung Wölfersheim befuhr, lief ein achtjähriges Mädchen direkt vor den Wagen.

'An 8-year old girl ran right in front of the car of a driver from Bad Nauheim who was driving down (lit. be-driving) Wetteraustreet in Dorheim towards Wölfersheim.'

${ }^{18}$ Both beputzen and bekochen take incremental themes; only bekochen, however, allows the theme to receive a deindividuated construal when it is expressed as an oblique. This suggests a necessary condition on oblique linking for themes: the theme must be construable as deindividuated, as per Brinkmann's Nonindividuation Hypothesis. Such a constraint would explain the ill formedness of resultative examples like* She cleaned herself into a frenzy with the house and the German example in 106. However, any theme is in principle construable as deindividuated-via pluralization in the case of singular count nouns, for example. The combination of beputzen with an oblique theme is equally ill formed when that theme is unbounded: *Sie beputzen Leute mit Küchen ('They be-clean people with [their] kitchens'). Therefore, we presume that the restriction on oblique themes among applicative verbs of domestic activity hinges on the validity of the transfer implication rather than a constraint involving deindividuation.

${ }^{19}$ Admittedly, however, the 'surrounding' usage does appear to be the source of a limited number of denominal coinages. The verb behausen acquired its bivalent sense of 'house, shelter' only after Grimm's time. Also, beheimaten 'provide a home for' in both bivalent and trivalent form is 
unattested in Grimm. Since no other formations with a surrounding sense have occurred, we consider these developments as analogical extensions on the model of beherbergen.

${ }^{20}$ The 'around' meaning seems to have already been lost in Middle High German in the case of the related preposition $b \hat{\imath}$, the source for Modern German bei 'by' (Lexer 1872). 